\title{
Study on the Mechanism of the Effect of \\ Temperature on the Decomposition Reaction of SFn $(n=1-6)$ under Discharge Conditions
}

Minghao Yang ( $\nabla$ ymh3119304251@stu.xjtu.edu.cn )

Xi'an Jiaotong University https://orcid.org/0000-0003-1758-4658

Jing Yan

Xi'an Jiaotong University

Mengyuan Xu

Xi'an Jiaotong University

Yingsan Geng

Xi'an Jiaotong University

Zhiyuan Liu

Xi'an Jiaotong University

Jianhua Wang

Xi'an Jiaotong University

\section{Research Article}

Keywords: gibbs free energy change, electronic impact, quantum chemistry, reaction mechanism

Posted Date: April 19th, 2021

DOl: https://doi.org/10.21203/rs.3.rs-388556/v1

License: (c) (1) This work is licensed under a Creative Commons Attribution 4.0 International License.

Read Full License

Version of Record: A version of this preprint was published at Journal of Molecular Modeling on August 5th, 2021. See the published version at https://doi.org/10.1007/s00894-021-04866-2. 


\title{
Study on the Mechanism of the Effect of Temperature on the Decomposition Reaction of $\mathrm{SF}_{\mathrm{n}}(\mathrm{n}=1-6)$ under Discharge Conditions
}

Minghao Yang, Jing Yan*, Mengyuan Xu, Yingsan Geng, Zhiyuan Liu and Jianhua Wang

Author to whom correspondence should be addressed: yanjing@mail.xjtu.edu.cn

State Key Laboratory of Electrical Insulation and Power Equipment

Xi'an Jiaotong University

Xi'an, P. R. China

\begin{abstract}
The study on the mechanism of the effect of temperature on the decomposition reaction of $\mathrm{SF}_{\mathrm{n}}$ $(n=1-6)$ under discharge conditions is very important in studying the potential fault of $\mathrm{SF}_{6}$ high voltage switch equipment and perfecting the chemical kinetic model of $\mathrm{SF}_{\mathrm{n}}$ discharge. In this paper, structural optimizations, vibrational frequency calculations, and zero-point energy calculations for the reactants and products were performed at the B3LYP/6-311++G(d,p) theory level. The single-point energies of all species were collected at the CCSD(T)/aug-cc-PVTZ level. The electric and thermal decomposition mechanism of $\mathrm{SF}_{\mathrm{n}}$ under discharge conditions of $298 \mathrm{~K}-10000 \mathrm{~K}$ were studied, respectively. The conclusion drawn was that in the temperature range of 298-10000K, the thermal decomposition homopolytic reaction $\triangle \mathrm{G}$ began to decline from 200 $\mathrm{kJ} / \mathrm{mol}$, while the $\triangle \mathrm{G}$ of the other two heterogenous reactions began to decrease from $1000 \mathrm{~kJ} / \mathrm{mol}$ and $2000 \mathrm{~kJ} / \mathrm{mol}$, showing a downward trend of an almost similar slope. The electrolysis of $\mathrm{SF}_{\mathrm{n}}$ is related to the electron energy. When the electron energy is low, $\mathrm{SF}_{\mathrm{n}}+\mathrm{e} \rightarrow \mathrm{SF}_{\mathrm{n}}{ }^{-}$series reactions occur, and $\triangle \mathrm{G}$ of R12, R20, R28, R36, R44 increases with temperature rise, while $\triangle \mathrm{G}$ of R4 decreases with temperature. When the electron energy is high, one of $\mathrm{SF}_{\mathrm{n}}{ }^{-} \rightarrow \mathrm{SF}_{\mathrm{n}-1^{-}}+\mathrm{F}$ 、 $\mathrm{SF}_{\mathrm{n}}{ }^{-} \rightarrow \mathrm{SF}_{\mathrm{n}-1}+\mathrm{F}^{-}$and $\mathrm{SF}_{\mathrm{n}}{ }^{-} \rightarrow \mathrm{SF}_{\mathrm{n}-1}+\mathrm{F}+\mathrm{e}$ will occur, and the reactions that occur at various temperature ranges as the temperature rises vary. When the second electron hits the $\mathrm{SF}_{\mathrm{n}}{ }^{-}$, the $\mathrm{SF}_{\mathrm{n}}{ }^{-}$ $+\mathrm{e} \rightarrow \mathrm{SF}_{\mathrm{n}-1}{ }^{-}+\mathrm{F}$ reaction will occur. The $\triangle \mathrm{G}$ of this reaction slowly decreases with an increase in temperature. This study in clearer terms explains the decomposition process and mechanism of $\mathrm{SF}_{\mathrm{n}}$ at different temperatures.
\end{abstract}

Keywords: gibbs free energy change, electronic impact, quantum chemistry, reaction mechanism

\section{INTRODUCTION}

$\mathrm{SF}_{6}$ high voltage switch equipment has a number of advantages. These include small size, high safety, and long maintenance period. With the improvement of power system voltage level, $\mathrm{SF}_{6}$ high voltage switch equipment use has drastically grown. $\mathrm{SF}_{6}$ is a colorless, tasteless, non-toxic, non-flammable stable gas. Because of its good electron affinity, thermodynamic stability and good dielectric property, it is commonly used as insulating medium and arc extinguishing medium for gas insulated equipment 1 . However, when partial discharge or arc discharge occurs in the equipment, $\mathrm{SF}_{6}$ gas will decompose on reacting with heat and electricity and form neutral low-flourine flourosulfur species, such as $\mathrm{SF}_{5}, \mathrm{SF}_{4}, \mathrm{SF}_{3}$, $\mathrm{SF}_{2}, \mathrm{SF}$, and anions $\mathrm{SF}_{6}^{-}, \mathrm{SF}_{5}^{-}, \mathrm{SF}_{4}^{-}, \mathrm{SF}_{3}{ }^{-}$, etc. 2-4. Most of the low-fluorine sulfides $(99.9 \%)$ will react with $\mathrm{F}$ atoms to regenerate $\mathrm{SF}_{6}$ in a very short period of time. But a small part will 
react with trace amount of water and oxygen inside the equipment in a series of complex chemical reactions, and finally produce $\mathrm{SOF}_{4}$, $\mathrm{SOF}_{2}, \mathrm{SO}_{2} \mathrm{~F}_{2}, \mathrm{HF}, \mathrm{SO}_{2}, \mathrm{CF}_{4}, \mathrm{CO}_{2}, \mathrm{CS}_{2}$ and other by-products ${ }^{5}$. As much as these products reduce the purity of $\mathrm{SF}_{6}$ gas and affect its insulation and arc extinguishing performance, they also corrode the metal parts and solid insulating materials in the equipment, lowering the durability of the equipment. On the other hand, the components and contents of some characteristic products can be utilized in evaluating the deterioration of the metal and solid insulating materials in the equipment, and to identify the discharge defects in the equipment.

Many scholars have done a lot of research on the decomposition products of $\mathrm{SF}_{6}$ under discharge conditions. Local overheating is an important cause of decomposition of $\mathrm{SF}_{6}$ molecule. Wilkins found through experimental research that at a temperature $1500 \mathrm{~K}$, the main decomposition product of $\mathrm{SF}_{6}$ gas is $\mathrm{SF}_{4}{ }^{6}$. $\mathrm{W}$. Frie used the counter ion concentration calculation method to roughly estimate the number of equilibrium particles in $\mathrm{SF}_{6}$ plasma at various temperatures ${ }^{7}$. It was found that when the temperature of $\mathrm{SF}_{6}$ gas was higher than $1500 \mathrm{~K}$, its concentration was significantly minimal, and the $\mathrm{SF}_{4}$ concentration and $\mathrm{F}$ atoms would rise rapidly. At temperatures higher than $4000 \mathrm{~K}$, most of the $\mathrm{SF}_{6}$ molecules would be completely decomposed, but the decomposition mechanism has not been further studied. Under arc discharge, electron collision is another key factor affecting the decomposition of $\mathrm{SF}_{6}$ molecules. As early as 1953, AJ Ahearn et al. discovered that the main products of $\mathrm{SF}_{6}$ molecules ionized by electron impact in vacuum are $\mathrm{SF}_{6}{ }^{-}, \mathrm{SF}_{5}{ }^{-}$and $\mathrm{F}^{-}$plasma ${ }^{8}$. Wiggart $\mathrm{N}$ and Wang $\mathrm{Y}$ et al. believed that $\mathrm{SF}_{6}$ was a strongly electronegative gas, which if combined with electrons would form metastable molecular group $\left(\mathrm{SF}_{6}\right)^{*}$. After a very short time, the molecular group will further generate $\mathrm{SF}_{6}^{-}, \mathrm{SF}_{5}^{-}, \mathrm{F}^{-}$and other anions. On further increase to the electron energy, $\mathrm{SF}_{4}{ }^{-}$, $\mathrm{SF}_{3}{ }^{-}$and other anion low-fluoride sulfide may be formed 9,10 . Zieglar et al. theoretically studied the decomposition process of anion low-fluoride sulfide, and found that further decomposition of $\mathrm{SF}_{5}^{-}, \mathrm{SF}_{4}^{-}, \mathrm{SF}_{3}^{-}, \mathrm{SF}_{2}^{-}, \mathrm{SF}^{-}$ and other anions would lead to a formation of a lower level of neutral low-fluoride sulfide molecule and an $\mathrm{F}^{-}$anion, but he did not take a keen note on the process in which electrons participate in the reaction ${ }^{2}$. Fifen found that the thermodynamic data of electrons would vary greatly with temperature change, and he corrected the thermodynamic data of 0-10000K through algorithm iteration ${ }^{11}$. Wang et al. studied the particle compositions of an $\mathrm{SF}_{6}$ arc using a two-temperature chemical kinetics model. The chemical reaction system consists of 18 particles, and 63 chemical reactions are taken into consideration. But they did not consider the effect of temperature change on the reaction, and did not include reactions involving $\mathrm{SF}_{2}{ }^{-}$ and $\mathrm{SF}_{3}{ }^{-}$. The chemical reaction equation was incomplete ${ }^{12}$.

Early research mainly focused on the qualitative analysis of the types of $\mathrm{SF}_{6}$ gas decomposition products. The thermal decomposition mechanism and electron impact decomposition mechanism of $\mathrm{SF}_{\mathrm{n}}$ at different temperatures has not been systematically studied. This paper systematically combs the decomposition process of $\mathrm{SF}_{\mathrm{n}}$, discharge decomposition products in different temperature ranges, and gives a detailed explanation of the decomposition process of $\mathrm{SF}_{\mathrm{n}}$ at different temperatures. In addition, it has certain guiding significance for a further study on the reaction of $\mathrm{SF}_{6}$ with micro water and micro oxygen at different temperatures. This paper 
uses quantum chemistry theory to systematically comb the decomposition products and processes of $\mathrm{SF}_{\mathrm{n}}$ at a temperature of $298-10000 \mathrm{~K}$. The second part describes the calculation method, and the third part provides the results and discussion. In addition, this article also has certain reference significance for establishing a complete arc plasma model.

\section{CALCULATION METHOD}

In this paper, quantum chemistry method is used to find out the reaction mechanism of $\mathrm{SF}_{\mathrm{n}}(\mathrm{n}=1-6)$ under overheating and electron impact conditions under discharge conditions. Table 1 lists all the reaction equations in this paper. It is divided into two types of processes: overheating decomposition and electron impact decomposition. Taking the decomposition of $\mathrm{SF}_{6}$ as an example, $\mathrm{R} 1$ is the process of covalent bond homolysis resulting from overheating, R2 and R3 are the process of covalent bond heterolysis, $\mathrm{R} 4$ and $\mathrm{R} 8$ are electron capture process while R5, R6, and R7 are decomposition processes resulting from R4.

Table 1. All reaction equations in this paper

\begin{tabular}{|c|c|}
\hline Serial number & Chemical reaction \\
\hline $\mathrm{R} 1$ & $\mathrm{SF}_{6} \rightarrow \mathrm{SF}_{5}+\mathrm{F}$ \\
\hline $\mathrm{R} 2$ & $\mathrm{SF}_{6} \rightarrow \mathrm{SF}_{5}^{+}+\mathrm{F}^{-}$ \\
\hline R3 & $\mathrm{SF}_{6} \rightarrow \mathrm{SF}_{5}^{-}+\mathrm{F}^{+}$ \\
\hline $\mathrm{R} 4$ & $\mathrm{SF}_{6}+\mathrm{e} \rightarrow \mathrm{SF}_{6}^{-}$ \\
\hline $\mathrm{R} 5$ & $\mathrm{SF}_{6}{ }^{-} \rightarrow \mathrm{SF}_{5}^{-}+\mathrm{F}$ \\
\hline R6 & $\mathrm{SF}_{6}^{-} \rightarrow \mathrm{SF}_{5}+\mathrm{F}^{-}$ \\
\hline R7 & $\mathrm{SF}_{6}-\mathrm{SF}_{5}+\mathrm{F}+\mathrm{e}$ \\
\hline $\mathrm{R} 8$ & $\mathrm{SF}_{6}^{-}+\mathrm{e} \rightarrow \mathrm{SF}_{5}^{-}+\mathrm{F}^{-}$ \\
\hline R9 & $\mathrm{SF}_{5} \rightarrow \mathrm{SF}_{4}+\mathrm{F}$ \\
\hline $\mathrm{R} 10$ & $\mathrm{SF}_{5} \rightarrow \mathrm{SF}_{4}^{+}+\mathrm{F}^{-}$ \\
\hline R11 & $\mathrm{SF}_{5} \rightarrow \mathrm{SF}_{4}^{-}+\mathrm{F}^{+}$ \\
\hline $\mathrm{R} 12$ & $\mathrm{SF}_{5}+\mathrm{e} \rightarrow \mathrm{SF}_{5}^{-}$ \\
\hline $\mathrm{R} 13$ & $\mathrm{SF}_{5}^{-} \rightarrow \mathrm{SF}_{4}^{-}+\mathrm{F}$ \\
\hline R14 & $\mathrm{SF}_{5}^{-} \rightarrow \mathrm{SF}_{4}+\mathrm{F}^{-}$ \\
\hline $\mathrm{R} 15$ & $\mathrm{SF}_{5}-\mathrm{SF}_{4}+\mathrm{F}+\mathrm{e}$ \\
\hline
\end{tabular}

\begin{tabular}{|c|c|}
\hline $\mathrm{R} 16$ & $\mathrm{SF}_{5}^{-}+\mathrm{e} \rightarrow \mathrm{SF}_{4}^{-}+\mathrm{F}^{-}$ \\
\hline $\mathrm{R} 17$ & $\mathrm{SF}_{4} \rightarrow \mathrm{SF}_{3}+\mathrm{F}$ \\
\hline $\mathrm{R} 18$ & $\mathrm{SF}_{4} \rightarrow \mathrm{SF}_{3}^{+}+\mathrm{F}^{-}$ \\
\hline R19 & $\mathrm{SF}_{4} \rightarrow \mathrm{SF}_{3}^{-}+\mathrm{F}^{+}$ \\
\hline $\mathrm{R} 20$ & $\mathrm{SF}_{4}+\mathrm{e} \rightarrow \mathrm{SF}_{4}^{-}$ \\
\hline $\mathrm{R} 21$ & $\mathrm{SF}_{4}^{-} \rightarrow \mathrm{SF}_{3}^{-}+\mathrm{F}$ \\
\hline $\mathrm{R} 22$ & $\mathrm{SF}_{4}^{-} \rightarrow \mathrm{SF}_{3}+\mathrm{F}^{-}$ \\
\hline $\mathrm{R} 23$ & $\mathrm{SF}_{4}^{-} \rightarrow \mathrm{SF}_{3}+\mathrm{F}+\mathrm{e}$ \\
\hline $\mathrm{R} 24$ & $\mathrm{SF}_{4}^{-}+\mathrm{e} \rightarrow \mathrm{SF}_{3}^{-}+\mathrm{F}^{-}$ \\
\hline $\mathrm{R} 25$ & $\mathrm{SF}_{3} \rightarrow \mathrm{SF}_{2}+\mathrm{F}$ \\
\hline R26 & $\mathrm{SF}_{3} \rightarrow \mathrm{SF}_{2}^{+}+\mathrm{F}^{-}$ \\
\hline $\mathrm{R} 27$ & $\mathrm{SF}_{3} \rightarrow \mathrm{SF}_{2}^{-}+\mathrm{F}^{+}$ \\
\hline $\mathrm{R} 28$ & $\mathrm{SF}_{3}+\mathrm{e} \rightarrow \mathrm{SF}^{-}$ \\
\hline $\mathrm{R} 29$ & $\mathrm{SF}_{3}^{-} \rightarrow \mathrm{SF}_{2}^{-}+\mathrm{F}$ \\
\hline R30 & $\mathrm{SF}_{3}^{-} \rightarrow \mathrm{SF}_{2}+\mathrm{F}^{-}$ \\
\hline R31 & $\mathrm{SF}_{3} \rightarrow \mathrm{SF}_{2}+\mathrm{F}+\mathrm{e}$ \\
\hline $\mathrm{R} 32$ & $\mathrm{SF}_{3}^{-}+\mathrm{e} \rightarrow \mathrm{SF}_{2}^{-}+\mathrm{F}^{-}$ \\
\hline R33 & $\mathrm{SF}_{2} \rightarrow \mathrm{SF}+\mathrm{F}$ \\
\hline R34 & $\mathrm{SF}_{2} \rightarrow \mathrm{SF}^{+}+\mathrm{F}^{-}$ \\
\hline $\mathrm{R} 35$ & $\mathrm{SF}_{2} \rightarrow \mathrm{SF}^{-}+\mathrm{F}^{+}$ \\
\hline $\mathrm{R} 36$ & $\mathrm{SF}_{2}+\mathrm{e} \rightarrow \mathrm{SF}_{2}^{-}$ \\
\hline $\mathrm{R} 37$ & $\mathrm{SF}_{2}^{-} \rightarrow \mathrm{SF}^{-}+\mathrm{F}$ \\
\hline $\mathrm{R} 38$ & $\mathrm{SF}_{2}^{-} \rightarrow \mathrm{SF}+\mathrm{F}^{-}$ \\
\hline R39 & $\mathrm{SF}_{2}-\mathrm{SF}+\mathrm{F}+\mathrm{e}$ \\
\hline $\mathrm{R} 40$ & $\mathrm{SF}_{2}^{-}+\mathrm{e} \rightarrow \mathrm{SF}^{-}+\mathrm{F}^{-}$ \\
\hline $\mathrm{R} 41$ & $\mathrm{SF} \rightarrow \mathrm{S}+\mathrm{F}$ \\
\hline $\mathrm{R} 42$ & $\mathrm{SF} \rightarrow \mathrm{S}^{+}+\mathrm{F}^{-}$ \\
\hline $\mathrm{R} 43$ & $\mathrm{SF} \rightarrow \mathrm{S}^{-}+\mathrm{F}^{+}$ \\
\hline $\mathrm{R} 44$ & $\mathrm{SF}+\mathrm{e} \rightarrow \mathrm{SF}^{-}$ \\
\hline $\mathrm{R} 45$ & $\mathrm{SF}^{-} \rightarrow \mathrm{S}-+\mathrm{F}$ \\
\hline $\mathrm{R} 46$ & $\mathrm{SF}^{-} \rightarrow \mathrm{S}+\mathrm{F}^{-}$ \\
\hline R47 & $\mathrm{SF}^{-} \rightarrow \mathrm{S}+\mathrm{F}+\mathrm{e}$ \\
\hline $\mathrm{R} 48$ & $\mathrm{SF}^{-}+\mathrm{e} \rightarrow \mathrm{S}^{-}+\mathrm{F}^{-}$ \\
\hline
\end{tabular}

Table 2. Entropy, enthalpy and Gibbs free energy of gaseous electrons

\begin{tabular}{|l|l|l|l|}
\hline $\begin{array}{c}\mathrm{T} \\
(\mathrm{K})\end{array}$ & $\begin{array}{c}\mathrm{S} \\
(\mathrm{J} / \mathrm{mol})\end{array}$ & $\begin{array}{c}\mathrm{H} \\
(\mathrm{kJ} / \mathrm{mol})\end{array}$ & $\begin{array}{c}\mathrm{G} \\
(\mathrm{kJ} / \mathrm{mol})\end{array}$ \\
\hline 298.15 & 22.6432 & 3.1351 & -3.616 \\
\hline 300 & 22.7491 & 3.1659 & -3.6588 \\
\hline 350 & 25.4629 & 4.0467 & -4.8653 \\
\hline 400 & 27.9153 & 4.9654 & -6.2008 \\
\hline 450 & 30.1427 & 5.9111 & -7.6531 \\
\hline
\end{tabular}




\begin{tabular}{|l|l|l|l|}
\hline 500 & 32.1769 & 6.8766 & -9.2118 \\
\hline 600 & 35.7696 & 8.8478 & -12.6139 \\
\hline 700 & 38.8607 & 0.8534 & -16.3491 \\
\hline 800 & 41.5666 & 12.88 & -20.3733 \\
\hline 900 & 43.9694 & 14.9201 & -24.6523 \\
\hline 1000 & 46.1284 & 16.9694 & -29.159 \\
\hline 2000 & 60.4503 & 37.6429 & -83.258 \\
\hline 3000 & 68.8664 & 58.4007 & -148.199 \\
\hline 4000 & 74.8428 & 79.1749 & -220.196 \\
\hline 5000 & 79.4797 & 99.9548 & -297.443 \\
\hline 6000 & 83.2687 & 120.7372 & -378.875 \\
\hline 7000 & 86.4725 & 141.5209 & -463.787 \\
\hline 8000 & 89.2479 & 162.3053 & -551.678 \\
\hline 9000 & 91.696 & 183.0902 & -642.174 \\
\hline 10000 & 93.886 & 203.8754 & -734.984 \\
\hline
\end{tabular}

Because of some limitations of Gaussian 09 in obtaining thermodynamic data, this paper used the KisTheIP to obtain thermodynamic data of all structures at $298-10000 \mathrm{~K}{ }^{15}$. KisTheIP is a program renown for calculating chemical reaction rates and thermodynamic data. It has many functions which include calculating thermodynamic data, calculating reaction equilibrium constants, calculating the reaction rate constants of single or bimolecular reactions by TST or VTST methods, and some more. For the record, KisTheIP cannot get the thermodynamic data of electrons. The thermodynamic data of electrons used in this paper uses the thermodynamic data mentioned in the Fifen's article as shown in Table 2, and

All the calculations of quantum chemistry in this study are completed in Gaussian $09{ }^{17}$. Gausian 09 is currently the most popular and powerful quantum chemical calculation software. So as to predict the accuracy of the outcome, the article uses M06-2X/def2-TZVP level and B3LYP/6-31G(d) level and B3LYP/6-311++G(d, P) level for verification and comparison. The above levels were used to optimize the structure of reactants and products, and calculate the vibration frequency and zero-point energy ${ }^{13}$. Thermodynamic data consists of the sum of single point energy and thermal correction. Because the calculation of the thermal correction does not require a high level of calculation to get a very accurate result. The thermal correction was obtained at the B3LY $\mathrm{P} / 6-311++\mathrm{G}(\mathrm{d}, \mathrm{p})$ level. Single point energy requires a high level of calculation to get accurate results, so single-point energy calculation was done at the CCSD(T)/aug-cc-PVTZ level ${ }^{14}$. To ensure accuracy in the calculated outcome, the frequency vibration factor is considered. When using the B3LYP/6-311++G(d, p) level, the frequency vibration factor is 0.967 . is derived to by fitting the cubic spline difference ${ }^{11}$. The Gibbs free energy of gas phase electrons changes with temperature as shown in Figure 1. After obtaining the thermodynamic data of all the structures, $\Delta \mathrm{G}$ of all the reactions in this paper was got by subtracting $G$ of the reactants from $G$ of the products. For example, at $298 \mathrm{~K}$, for the reaction $\mathrm{SF}_{6} \rightarrow \mathrm{SF}_{5}+\mathrm{F}$ in Table 3, the $\mathrm{G}$ of the reactant $\mathrm{SF}_{6}$ is -996.1496484 Hartree, the $\mathrm{G}$ of the product $\mathrm{SF}_{5}$ is -896.3641003 Hartree, the $\mathrm{G}$ of $\mathrm{F}$ is -99.64262951 Hartree, the $\Delta \mathrm{G}$ of this reaction is:

$\Delta G=(-896.3641-99.6426295+996.1496484)$ $\times 2625.5=375.2 \mathrm{~kJ} / \mathrm{mol}$

Calculate the $\triangle \mathrm{G}$ of all reactions in the temperature range of $298-10000 \mathrm{~K}$, and get the curve in Figure 3-10.

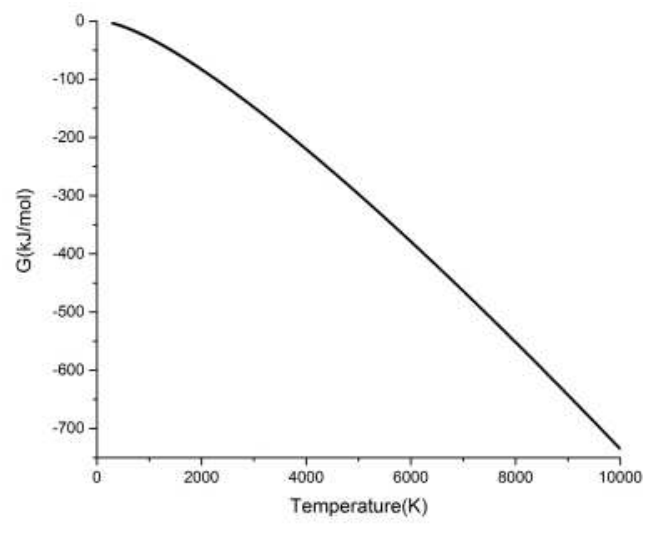


Figure 1. Gibbs free energy of gas phase electrons changes with temperature

\section{RESULTS AND DISCUSSION}

3.1 STRUCTURAL OPTIMIZATIONS AND ENERGIES

The optimized structure of reactants and products in reaction R1-R48 is displayed in Figure 2. In this paper, structural optimization was performed at the B3LYP/6-311++G(d,p) level of theory. The optimized structure of all neutral reactants and products was compared with the experimental geometric data in the NIST database and the outcomes of other theoretical calculations (B3LYP/6-31g (d)) ${ }^{18}$. The structural parameters of all reactants and products coincide with the literature of Tom Ziegler and Cheung 2,16. The key structural parameters are shown in Figures 2. The B3LYP/6-311++G(d, p) level not only provides excellent computing accuracy, but also significantly saves computing resources. In comparison to the experimental data, the bond Angle error of all structures was $<0.1 \AA$, and the bond length error of all structures was $<2.6^{\circ}$. The error mainly results from the difference of theoretical level.

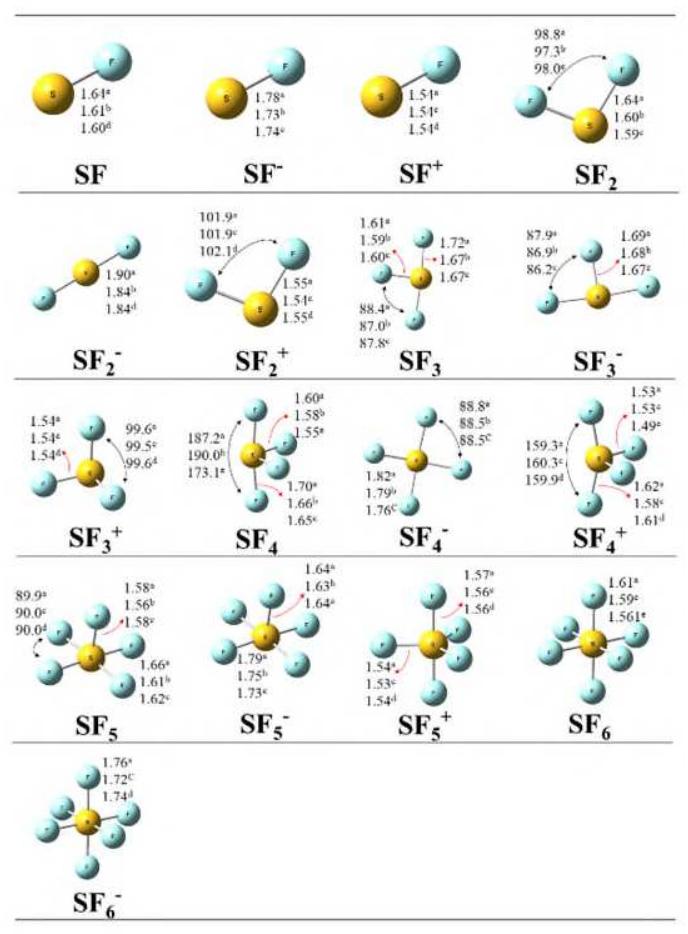

Figure 2. Optimized structures of all reactants and products. (Bond lengths are in angstroms and bond angles are in degrees.)

a. B3LYP/6-311++G(d, p) level in the present work.

b. Equilibrium structures in the Tom Ziegler's work.

c. Equilibrium structures in the Cheung's work.

d. B3LYP/6-31G(d) level in the NIST database.

e. Experimental geometry data in the NIST database.

Table 3. $\triangle \mathrm{G}$ of reactions at 298,5000 , and $10000 \mathrm{~K}$

\begin{tabular}{|c|c|c|c|}
\hline Chemical reaction & $298 K$ & $5000 \mathrm{~K}$ & $10000 \mathrm{~K}$ \\
\hline $\mathrm{SF}_{6} \rightarrow \mathrm{SF}_{5}+\mathrm{F}$ & 375.2 & -434.3 & -1274.0 \\
\hline $\mathrm{SF}_{6} \rightarrow \mathrm{SF}_{5}^{+}+\mathrm{F}^{-}$ & 1004.3 & 334.5 & -353.0 \\
\hline $\mathrm{SF}_{6} \rightarrow \mathrm{SF}_{5}{ }^{-}+\mathrm{F}^{+}$ & 1913.5 & 1010.7 & 70.0 \\
\hline $\mathrm{SF}_{6}+\mathrm{e} \rightarrow \mathrm{SF}_{6}$ & -126.1 & -246.5 & -255.5 \\
\hline $\mathrm{SF}_{6}{ }^{-} \rightarrow \mathrm{SF}_{5}-\mathrm{F}$ & 105.2 & -410.4 & -933.3 \\
\hline $\mathrm{SF}_{6} \rightarrow \mathrm{SF}_{5}+\mathrm{F}^{-}$ & 187.1 & -181.1 & -545.4 \\
\hline $\mathrm{SF}_{6}-\mathrm{SF}_{5}+\mathrm{F}+\mathrm{e}$ & 501.3 & -187.8 & -1018.5 \\
\hline $\mathrm{SF}_{6}{ }^{-}+\mathrm{e} \rightarrow \mathrm{SF}_{5}^{-}+\mathrm{F}^{-}$ & -209.0 & -403.6 & -460.3 \\
\hline
\end{tabular}




\begin{tabular}{|c|c|c|c|}
\hline $\mathrm{SF}_{5} \rightarrow \mathrm{SF}_{4}+\mathrm{F}$ & -53.4 & -867.5 & -1712.1 \\
\hline $\mathrm{SF}_{5} \rightarrow \mathrm{SF}_{4}^{+}+\mathrm{F}^{-}$ & 936.2 & 309.1 & -333.3 \\
\hline $\mathrm{SF}_{5} \rightarrow \mathrm{SF}_{4}^{-}+\mathrm{F}^{+}$ & 1884.6 & 1097.6 & 281.8 \\
\hline $\mathrm{SF}_{5}+\mathrm{e} \rightarrow \mathrm{SF}_{5}^{-}$ & -396.1 & -222.5 & 85.2 \\
\hline $\mathrm{SF}_{5}^{-} \rightarrow \mathrm{SF}_{4}^{-}+\mathrm{F}$ & 346.4 & -347.5 & -1062.2 \\
\hline $\mathrm{SF}_{5}^{-} \rightarrow \mathrm{SF}_{4}+\mathrm{F}^{-}$ & 215.9 & -267.7 & -756.0 \\
\hline $\mathrm{SF}_{5}^{-} \rightarrow \mathrm{SF}_{4}+\mathrm{F}+\mathrm{e}$ & 530.1 & -274.4 & -1229.1 \\
\hline $\mathrm{SF}_{5}^{-}+\mathrm{e} \rightarrow \mathrm{SF}_{4}^{-}+\mathrm{F}^{-}$ & 32.2 & -340.7 & -589.2 \\
\hline $\mathrm{SF}_{4} \rightarrow \mathrm{SF}_{3}+\mathrm{F}$ & 372.6 & -300.6 & -993.6 \\
\hline $\mathrm{SF}_{4} \rightarrow \mathrm{SF}_{3}^{+}+\mathrm{F}^{-}$ & 1120.3 & 590.6 & 52.6 \\
\hline $\mathrm{SF}_{4} \rightarrow \mathrm{SF}_{3}^{-}+\mathrm{F}^{+}$ & 1954.0 & 1303.4 & 633.4 \\
\hline $\mathrm{SF}_{4}+\mathrm{e} \rightarrow \mathrm{SF}_{4}^{-}$ & -183.7 & -73.0 & 166.8 \\
\hline $\mathrm{SF}_{4}^{-} \rightarrow \mathrm{SF}_{3}^{-}+\mathrm{F}$ & 203.3 & -291.2 & -792.3 \\
\hline $\mathrm{SF}_{4}^{-} \rightarrow \mathrm{SF}_{3}+\mathrm{F}^{-}$ & 242.1 & -220.8 & -687.4 \\
\hline $\mathrm{SF}_{4}^{-} \rightarrow \mathrm{SF}_{3}+\mathrm{F}+\mathrm{e}$ & 556.3 & -227.6 & -1160.4 \\
\hline $\mathrm{SF}_{4}^{-}+\mathrm{e} \rightarrow \mathrm{SF}_{3}^{-}+\mathrm{F}^{-}$ & -110.9 & -284.4 & -319.3 \\
\hline $\mathrm{SF}_{3} \rightarrow \mathrm{SF}_{2}+\mathrm{F}$ & 144.5 & -371.7 & -896.4 \\
\hline $\mathrm{SF}_{3} \rightarrow \mathrm{SF}_{2}{ }^{+}+\mathrm{F}^{-}$ & 819.6 & 329.8 & -165.8 \\
\hline $\mathrm{SF}_{3} \rightarrow \mathrm{SF}_{2}^{-}+\mathrm{F}^{+}$ & 2007.5 & 1568.5 & 1149.4 \\
\hline $\mathrm{SF}_{3}+\mathrm{e} \rightarrow \mathrm{SF}^{-}$ & -353.0 & -63.6 & 368.1 \\
\hline $\mathrm{SF}_{3}^{-} \rightarrow \mathrm{SF}_{2}^{-}+\mathrm{F}$ & 426.1 & -35.5 & -477.6 \\
\hline $\mathrm{SF}_{3}^{-} \rightarrow \mathrm{SF}_{2}+\mathrm{F}^{-}$ & 183.3 & -301.4 & -791.4 \\
\hline $\mathrm{SF}_{3}-\mathrm{SF}_{2}+\mathrm{F}+\mathrm{e}$ & 497.5 & -308.1 & -1264.5 \\
\hline $\mathrm{SF}_{3}^{-}+\mathrm{e} \rightarrow \mathrm{SF}_{2}^{-}+\mathrm{F}^{-}$ & 111.9 & -28.8 & -4.5 \\
\hline $\mathrm{SF}_{2} \rightarrow \mathrm{SF}+\mathrm{F}$ & 303.5 & -223.3 & -784.7 \\
\hline $\mathrm{SF}_{2} \rightarrow \mathrm{SF}^{+}+\mathrm{F}^{-}$ & 1117.2 & 657.3 & 167.5 \\
\hline $\mathrm{SF}_{2} \rightarrow \mathrm{SF}^{-}+\mathrm{F}^{+}$ & 2033.3 & 1544.5 & 1023.0 \\
\hline $\mathrm{SF}_{2}+\mathrm{e} \rightarrow \mathrm{SF}_{2}^{-}$ & -71.4 & 272.6 & 786.9 \\
\hline $\mathrm{SF}_{2}^{-} \rightarrow \mathrm{SF}^{-}+\mathrm{F}$ & 170.3 & -395.7 & -1022.8 \\
\hline $\mathrm{SF}_{2}^{-} \rightarrow \mathrm{SF}+\mathrm{F}^{-}$ & 60.7 & -489.1 & -1098.5 \\
\hline $\mathrm{SF}_{2}{ }^{-} \rightarrow \mathrm{SF}+\mathrm{F}+\mathrm{e}$ & 374.9 & -495.9 & -1571.6 \\
\hline $\mathrm{SF}_{2}^{-}+\mathrm{e} \rightarrow \mathrm{SF}^{-}+\mathrm{F}^{-}$ & 64.3 & -191.6 & -363.6 \\
\hline $\mathrm{SF} \rightarrow \mathrm{S}+\mathrm{F}$ & 302.9 & -173.1 & -705.6 \\
\hline $\mathrm{SF} \rightarrow \mathrm{S}^{+}+\mathrm{F}^{-}$ & 1172.5 & 739.5 & 252.7 \\
\hline $\mathrm{SF} \rightarrow \mathrm{S}^{-}+\mathrm{F}^{+}$ & 2053.8 & 1620.8 & 1134.0 \\
\hline $\mathrm{SF}+\mathrm{e} \rightarrow \mathrm{SF}^{-}$ & -204.6 & 100.2 & 548.8 \\
\hline $\mathrm{SF}^{-} \rightarrow \mathrm{S}-+\mathrm{F}$ & 324.1 & -147.0 & -673.7 \\
\hline $\mathrm{SF}^{-} \rightarrow \mathrm{S}+\mathrm{F}^{-}$ & 193.2 & -266.6 & -781.3 \\
\hline $\mathrm{SF}^{-} \rightarrow \mathrm{S}+\mathrm{F}+\mathrm{e}$ & 507.4 & -273.3 & -1254.4 \\
\hline $\mathrm{SF}^{-}+\mathrm{e} \rightarrow \mathrm{S}^{-}+\mathrm{F}^{-}$ & 9.9 & -140.2 & -200.6 \\
\hline
\end{tabular}

Table 3 shows the $\triangle \mathrm{G}$ of all reactions at 298K, 5000K, and 10000K. From the data in
Table 3, we can roughly see the trend of the $\triangle G$ of reactions with the change of temperature, which is more clearly compared with Figure 3-10. The $\triangle \mathrm{G}$ is in $\mathrm{kJ} / \mathrm{mol}$ in Table 3.

\subsection{REACTION MECHANISMS}

During the installation and operation of $\mathrm{SF}_{6}$ high voltage switchgear, electrode surface burrs, free conducting particles and suspension potential may exist in the equipment, leading to partial discharge or overheating in the equipment, making the gas temperature near the fault center higher compared to the ambient temperature. Under the parameters of arc and spark discharge, the decomposition of $\mathrm{SF}_{6}$ mostly results from electron impact or high temperature. Under partial discharge and corona discharge, $\mathrm{SF}_{6}$ dissociation is as a result of electron collisions in the discharge area due to low temperature. In this paper, the influence of different temperature on $\mathrm{SF}_{\mathrm{n}}$ decomposition reaction is considered, and Gibbs free energy is utilized in the analysis of each reaction.

3.2.1 Thermal decomposition of $\mathrm{SF}_{\mathrm{n}}(\mathrm{n}=1 \sim 6)$ under overheating conditions

The $\mathrm{SF}_{6}$ discharge decomposition reaction equation of $\mathrm{SF}_{6}$ high voltage switchgear is shown in Table 1. As Table 1 displays, the decomposition of $\mathrm{SF}_{6}$ is the process of S-F bond breaking in its molecular structure to form free radicals. The thermal decomposition process of $\mathrm{SF}_{6}$ may be directly decomposed into $\mathrm{SF}_{5}$ and $\mathrm{F}$ atoms, or heterocracking of covalent bonds may lead to formation of $\mathrm{SF}_{5}{ }^{+}, \mathrm{F}^{-}$, or $\mathrm{SF}_{5}^{-}, \mathrm{F}^{+}$. Figure 3 shows the change of $\triangle \mathrm{G}$ of $\mathrm{R} 1, \mathrm{R} 2$, and $\mathrm{R} 3$ at the temperature of $298-10000 \mathrm{~K}$. Figure 3 shows that the $\triangle G$ of R1-R3 decreases linearly with the increase of temperature. The $\triangle \mathrm{G}$ of $\mathrm{R} 1$ at $298 \mathrm{~K}$ is $375.2 \mathrm{~kJ} / \mathrm{mol}$. When the 
temperature reaches about $2450 \mathrm{~K}, \triangle \mathrm{G}$ falls below $0 \mathrm{~kJ} / \mathrm{mol}$, and the reaction can proceed spontaneously. When the temperature reaches $10000 \mathrm{~K}, \triangle \mathrm{G}$ drops to $-1274 \mathrm{~kJ} / \mathrm{mol}$. The $\triangle \mathrm{G}$ of $\mathrm{R} 2$ at $298 \mathrm{~K}$ is $1004.3 \mathrm{~kJ} / \mathrm{mol}$, when the temperature reaches about $7400 \mathrm{~K}$, the $\triangle \mathrm{G}$ of reaction can drop below $0 \mathrm{~kJ} / \mathrm{mol}$, when the temperature reaches $10000 \mathrm{~K}$, the $\triangle \mathrm{G}$ of reaction is $-353 \mathrm{~kJ} / \mathrm{mol}$. The $\Delta \mathrm{G}$ of $\mathrm{R} 3$ at $298 \mathrm{~K}$ is $1913.5 \mathrm{~kJ} / \mathrm{mol}$, when the temperature reaches $10000 \mathrm{~K}, \triangle \mathrm{G}$ is $70 \mathrm{~kJ} / \mathrm{mol}$, and it does not drop below $0 \mathrm{~kJ} / \mathrm{mol}$. Therefore, for the thermal decomposition process of $\mathrm{SF}_{6}, \mathrm{R} 1$ is most likely to occur within the temperature range of 298-10000K.

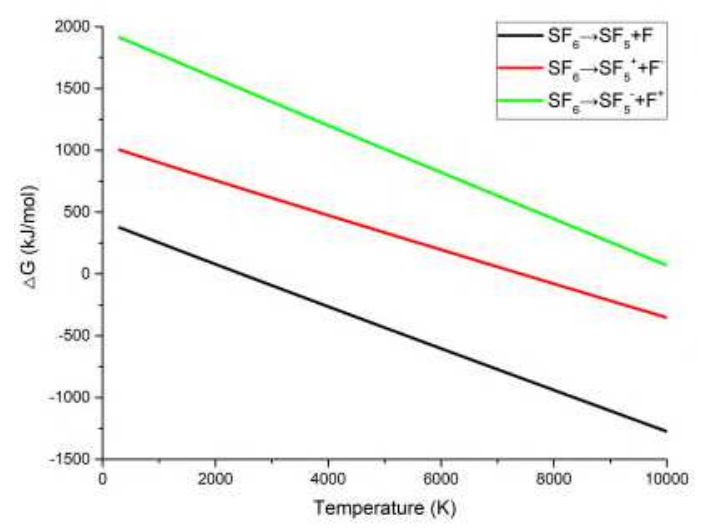

Figure 3. $\mathrm{SF}_{6}$ thermal decomposition $\triangle \mathrm{G}$ changes with temperature

The thermal decomposition process of $\mathrm{SF}_{5}$ may directly decompose $\mathrm{SF}_{4}$ and $\mathrm{F}$ atoms, or the covalent bond may heterocrack to produce $\mathrm{SF}_{4}^{+}, \mathrm{F}^{-}$, or $\mathrm{SF}_{4}^{-}, \mathrm{F}^{+}$. The $\mathrm{SF}_{5}$ thermal decomposition $\triangle \mathrm{G}$ changes with temperature as Figure 4 shows. It can be seen from Figure 4 that $\triangle \mathrm{G}$ of R9-R11 also decreases linearly with the temperature rise. During the thermal decomposition of $\mathrm{SF}_{5}$, the $\triangle \mathrm{G}$ of $\mathrm{R} 9$ at $298 \mathrm{~K}$ is $-53.4 \mathrm{~kJ} / \mathrm{mol}$, when the temperature reaches $10000 \mathrm{~K}$, the $\triangle \mathrm{G}$ decreases to $-1712.1 \mathrm{~kJ} / \mathrm{mol}$. The $\Delta \mathrm{G}$ of $\mathrm{R} 10$ at $298 \mathrm{~K}$ is $936.2 \mathrm{~kJ} / \mathrm{mol}$, when the temperature reaches about $7400 \mathrm{~K}, \triangle \mathrm{G}$ drops below $0 \mathrm{~kJ} / \mathrm{mol}$, and the reaction can be spontaneous. When the temperature reaches 10000K, $\triangle \mathrm{G}$ drops to $-333.3 \mathrm{~kJ} / \mathrm{mol}$. The $\triangle \mathrm{G}$ of $\mathrm{R} 11$ at $298 \mathrm{~K}$ is $1884.6 \mathrm{~kJ} / \mathrm{mol}$, when the temperature reaches $10000 \mathrm{~K}, \triangle \mathrm{G}$ decreases to $281.8 \mathrm{~kJ} / \mathrm{mol}$. Therefore, for the thermal decomposition process of $\mathrm{SF}_{5}$, $\mathrm{R} 9$ will most probably occur within the temperature range of $298-10000 \mathrm{~K}$.

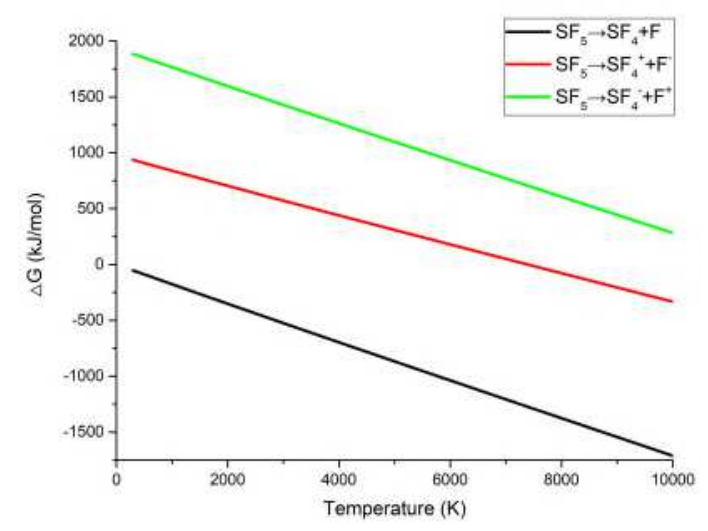

Figure $4 . \mathrm{SF}_{5}$ thermal decomposition $\triangle \mathrm{G}$ changes with temperature

From the above analysis, it can be seen that $\triangle \mathrm{G}$ of $\mathrm{SF}_{\mathrm{n}}$ displayed similar thermal decomposition rules within the temperature range of $298-10000 \mathrm{~K}$, and there was a decrease in energy required for the reaction as the temperature increased. Moreover, the energy required for the homolytic reaction is far less than the other two heterolytic reactions, so the homolytic reaction is most probable to take place. This is because $\mathrm{SF}_{\mathrm{n}}$ and $\mathrm{F}$ are both highly electronegative molecules. It is very hard for each molecule to lose electron and need to absorb a lot of energy. In addition, the same is the heterolytic dissociation, the reactions R2 and R10 can proceed spontaneously as the temperature increases, but the reactions R3 and R11 still cannot proceed spontaneously at very high temperatures. This is because the electronegativity of $\mathrm{F}$ is greater than that of $\mathrm{SF}_{\mathrm{n}}(\mathrm{n}=1-5)$, so the stability of $\mathrm{SF}_{\mathrm{n}}{ }^{+}$in the product is better than $\mathrm{F}^{+}{ }^{19}$. The reaction process curve and mechanism of other reactants $\mathrm{SF}_{\mathrm{m}}(\mathrm{m}=1-4)$ are similar to that of $\mathrm{SF}_{5}$ and $\mathrm{SF}_{6}$. Please refer to the supplementary materials for details. 
3.2.2 The electron impact decomposition process of $\mathrm{SF}_{\mathrm{n}}(\mathrm{n}=1-6)$

$\mathrm{SF}_{\mathrm{n}}$ in gas insulation equipment will be decomposed by energy because of electron impact in addition to simple thermal decomposition. Figure 5 shows the change of $\triangle \mathrm{G}$ of R4-R8 reaction at $298-10000 K$. From Figure 5 we realize that $\triangle \mathrm{G}$ of $\mathrm{R} 4-\mathrm{R} 8$ showed a decreasing trend with the increase of temperature. $\mathrm{SF}_{6}$ is a highly electronegative gas. When the energy of electrons in space is low, $\mathrm{SF}_{6}$ can be combined with electrons in space to form a metastable molecular group $\left(\mathrm{SF}_{6}\right)^{*}$. In a short while, this molecular group can further generate anion $\mathrm{SF}_{6}$. That is, $\mathrm{R} 4$ : $\mathrm{SF}_{6}+\mathrm{e} \rightarrow \mathrm{SF}_{6}$. When the temperature is $298 \mathrm{~K}$, $\triangle \mathrm{G}$ is $126.1 \mathrm{~kJ} / \mathrm{mol}$, when the temperature rises to $5000 \mathrm{~K}, \triangle \mathrm{G}$ is $-246.5 \mathrm{~kJ} / \mathrm{mol}$, when the temperature reaches $10000 \mathrm{~K}, \triangle \mathrm{G}$ is $-255.5 \mathrm{~kJ} / \mathrm{mol}$. With the temperature rise, the $\triangle \mathrm{G}$ of this reaction was less than zero, so it could proceed spontaneously.

When electrons continue to hit $\mathrm{SF}_{6}^{-}, \mathrm{R} 8$ : $\mathrm{SF}_{6}^{-}+\mathrm{e} \rightarrow \mathrm{SF}_{5}^{-}+\mathrm{F}-$ occurs. When the temperature is $298 \mathrm{~K}, \triangle \mathrm{G}$ is $209 \mathrm{~kJ} / \mathrm{mol}$, when the temperature rises to $5000 \mathrm{~K}, \triangle \mathrm{G}$ is $-403.6 \mathrm{~kJ} / \mathrm{mol}$, when the temperature reaches $10000 \mathrm{~K}, \triangle \mathrm{G}$ is $-460.3 \mathrm{~kJ} / \mathrm{mol}$. The $\Delta \mathrm{G}$ of this reaction is also less than zero, and goes on spontaneously.

When the energy of electrons hitting $\mathrm{SF}_{6}$ is high, $\mathrm{SF}_{6}+\mathrm{e} \rightarrow \mathrm{SF}_{6}$ - reaction will occur first, and then $\mathrm{SF}_{6}{ }^{-}$will be decomposed because of the huge energy of electrons, and three reactions of R5-R7 may occur: $\mathrm{SF}_{6} \rightarrow \mathrm{SF}_{5}{ }^{-}+\mathrm{F}$, $\mathrm{SF}_{6}-\mathrm{SF}_{5}+\mathrm{F}^{-}, \mathrm{SF}_{6}{ }^{-} \rightarrow \mathrm{SF}_{5}+\mathrm{F}+$ e. At a temperature $298 \mathrm{~K}$, the $\triangle \mathrm{G}$ of $\mathrm{R} 5$ is 105.2 $\mathrm{kJ} / \mathrm{mol}$, with a rise to about $1200 \mathrm{~K}$, it decreases to $0 \mathrm{~kJ} / \mathrm{mol}$, when the temperature reaches $10000 \mathrm{~K}$, the $\Delta \mathrm{G}$ is $-933.3 \mathrm{~kJ} / \mathrm{mol}$. The $\triangle \mathrm{G}$ of $\mathrm{R} 6$ at $298 \mathrm{~K}$ is $105.2 \mathrm{~kJ} / \mathrm{mol}$, when the temperature increases to about $2600 \mathrm{~K}$, it drops to $0 \mathrm{~kJ} / \mathrm{mol}$, when the temperature reaches $10000 \mathrm{~K}, \triangle \mathrm{G}$ is $-545.4 \mathrm{~kJ} / \mathrm{mol}$. The $\triangle \mathrm{G}$ of $\mathrm{R} 7$ at $298 \mathrm{~K}$ is $501.3 \mathrm{~kJ} / \mathrm{mol}$, when the temperature rises to about $3800 \mathrm{~K}$, it drops to 0 $\mathrm{kJ} / \mathrm{mol}$, and when the temperature reaches $10000 \mathrm{~K}$, the $\triangle \mathrm{G}$ is $-1018.5 \mathrm{~kJ} / \mathrm{mol}$. Since the curve of reaction $\mathrm{R} 5-7$ has an intersection point in the temperature range of $298-10000 \mathrm{~K}$, the reaction that takes place with temperature rise varies. At 298-8700K, R5 has the lowest $\triangle \mathrm{G}$, so it is most likely to occur. The reaction produces $\mathrm{SF}_{5}{ }^{-}$and $\mathrm{F}$. The $\triangle \mathrm{G}$ of $\mathrm{R} 7$ is the lowest at $8700-10000 \mathrm{~K}$, and the probability of $\mathrm{R} 7$ is greater in this temperature range.

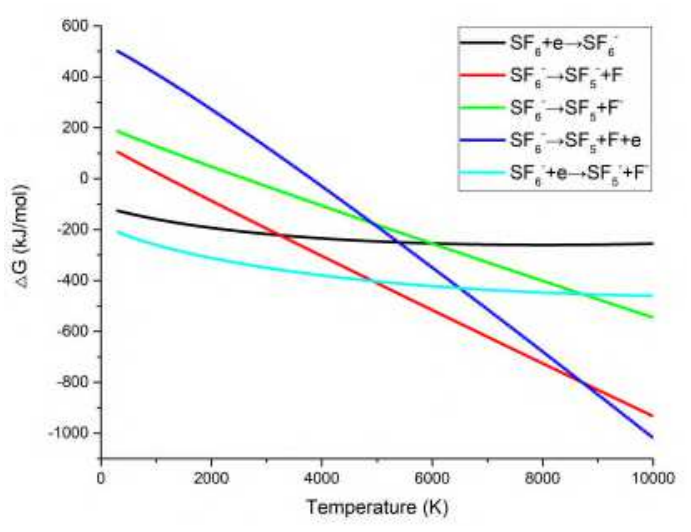

Figure 5. $\mathrm{SF}_{6}$ electron impact decomposition process $\triangle \mathrm{G}$ changes with temperature

Figure 6 shows the change of $\Delta G$ of the R12-R16 reaction at a temperature of $298-10000 K$. It can be seen from Figure 6 that the $\triangle \mathrm{G}$ of R13-R16 shows a downward trend with temperature rise, but the $\triangle \mathrm{G}$ of $\mathrm{R} 12$ increases with increasing temperature. When the electron energy in the space is low, the $\mathrm{R} 12$ reaction will occur: $\mathrm{SF}_{5}+\mathrm{e} \rightarrow \mathrm{SF}_{5}$. When the temperature is $298 \mathrm{~K}$, the $\triangle \mathrm{G}$ is -396.1 $\mathrm{kJ} / \mathrm{mol}$, when the temperature is increased to $5000 \mathrm{~K}$, the $\triangle \mathrm{G}$ is $-222.5 \mathrm{~kJ} / \mathrm{mol}$, when the temperature reaches $10000 \mathrm{~K}$, the $\Delta \mathrm{G}$ is $85.2 \mathrm{~kJ} / \mathrm{mol}$, showing an upward trend with increased temperature.

When electrons continue to hit $\mathrm{SF}_{5}{ }^{-}, \mathrm{R} 16$ will occur: $\mathrm{SF}_{5}^{-}+\mathrm{e} \rightarrow \mathrm{SF}_{4}^{-}+\mathrm{F}^{-}$. When the temperature of $\mathrm{R} 16$ is $298 \mathrm{~K}, \Delta \mathrm{G}$ is $32.2 \mathrm{~kJ} / \mathrm{mol}$, when the temperature is increased 
to $5000 \mathrm{~K}, \triangle \mathrm{G}$ is $-340.7 \mathrm{~kJ} / \mathrm{mol}$, when the temperature reaches $10000 \mathrm{~K}, \triangle \mathrm{G}$ is -589.2 $\mathrm{kJ} / \mathrm{mol}$. At $298 \mathrm{~K}$, the $\Delta \mathrm{G}$ of this reaction is very low and it is likely to take place. With increase in temperature, the reaction can proceed spontaneously.

When the energy of electrons hitting $\mathrm{SF}_{5}$ is high, $\mathrm{SF}_{5}+\mathrm{e} \rightarrow \mathrm{SF}_{5}{ }^{-}$reaction will occur first, and then $\mathrm{SF}_{5}{ }^{-}$will be decomposed as a result of the huge energy of electrons, and three reactions R13-R15 may occur: $\mathrm{SF}_{5}{ }^{-} \rightarrow \mathrm{SF}_{4}{ }^{-}+\mathrm{F}$ 、 $\mathrm{SF}_{5}{ }^{-} \rightarrow \mathrm{SF}_{4}+\mathrm{F}^{-} 、 \mathrm{SF}_{5}{ }^{-} \rightarrow \mathrm{SF}_{4}+\mathrm{F}+\mathrm{e}$. When the temperature is $298 \mathrm{~K}$, the $\triangle \mathrm{G}$ of $\mathrm{R} 13$ is $346.4 \mathrm{~kJ} / \mathrm{mol}$, when the temperature rises to about $2600 \mathrm{~K}$, it drops to $0 \mathrm{~kJ} / \mathrm{mol}$, and when the temperature reaches $10000 \mathrm{~K}$, the $\Delta \mathrm{G}$ is $-1062.2 \mathrm{~kJ} / \mathrm{mol}$. The $\Delta \mathrm{G}$ of $\mathrm{R} 14$ at $298 \mathrm{~K}$ is $215.9 \mathrm{~kJ} / \mathrm{mol}$, when the temperature rises to about $2300 \mathrm{~K}$, it drops to $0 \mathrm{~kJ} / \mathrm{mol}$, and when the temperature reaches $10000 \mathrm{~K}$, the $\Delta \mathrm{G}$ is $-756 \mathrm{~kJ} / \mathrm{mol}$. The $\triangle \mathrm{G}$ of $\mathrm{R} 15$ at $298 \mathrm{~K}$ is 530.1 $\mathrm{kJ} / \mathrm{mol}$, when the temperature rises to about $3500 \mathrm{~K}$, it drops to $0 \mathrm{~kJ} / \mathrm{mol}$, and when the temperature reaches $10000 \mathrm{~K}$, the $\Delta \mathrm{G}$ is $-1229.1 \mathrm{~kJ} / \mathrm{mol}$. In the temperature range of 298-3250K, the $\triangle \mathrm{G}$ of $\mathrm{R} 14$ is the lowest, so there is a high likelihood of occurrence. The reaction produces $\mathrm{SF}_{4}$ and $\mathrm{F}^{-}$. At $3250-6700 \mathrm{~K}$, the $\triangle \mathrm{G}$ of $\mathrm{R} 13$ is the lowest, and the probability of occurrence of R13 is higher in this temperature range. When the temperature continues to rise to $6700-10000 \mathrm{~K}$, the probability of R15 is greatest.

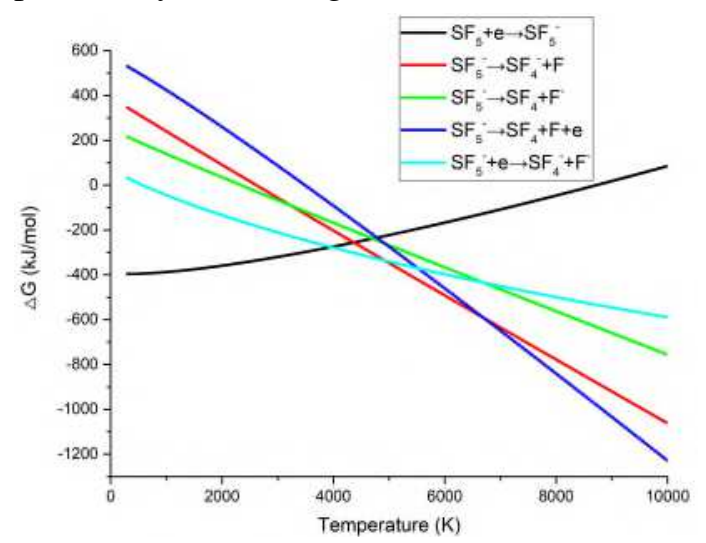

Figure 6. $\mathrm{SF}_{5}$ electron impact decomposition process $\triangle \mathrm{G}$ changes with temperature

Figure 7 shows the change of $\Delta G$ of the R20-R24 reaction at a temperature of $298-10000 K$. It can be seen from Figure 7 that the $\triangle \mathrm{G}$ of R21-R24 displays a downward trend with increasing temperature, but the $\triangle \mathrm{G}$ of R20 rises with increasing temperature. When the electron energy in the space is low, the $\mathrm{R} 20$ reaction will occur: $\mathrm{SF}_{4}+\mathrm{e} \rightarrow \mathrm{SF}_{4}$. When the temperature is $298 \mathrm{~K}$, the $\triangle \mathrm{G}$ is $-183.7 \mathrm{~kJ} / \mathrm{mol}$, when the temperature is increased to $5000 \mathrm{~K}$, the $\triangle \mathrm{G}$ is $-73 \mathrm{~kJ} / \mathrm{mol}$, when the temperature reaches $10000 \mathrm{~K}$, the $\triangle \mathrm{G}$ is $166.8 \mathrm{~kJ} / \mathrm{mol}$, showing an upward trend with increased temperature.

When electrons continue to hit $\mathrm{SF}_{4}^{-}, \mathrm{R} 24$ will occur: $\mathrm{SF}_{4}^{-}+\mathrm{e} \rightarrow \mathrm{SF}_{3}^{-}+\mathrm{F}^{-}$. When the temperature of $\mathrm{R} 24$ is $298 \mathrm{~K}, \Delta \mathrm{G}$ is $-110.9 \mathrm{~kJ} / \mathrm{mol}$, when the temperature is increased to $5000 \mathrm{~K}, \triangle \mathrm{G}$ is $-284.4 \mathrm{~kJ} / \mathrm{mol}$, when the temperature reaches $10000 \mathrm{~K}, \triangle \mathrm{G}$ is $-319.3 \mathrm{~kJ} / \mathrm{mol}$. The $\triangle \mathrm{G}$ of this reaction is less than zero, so it can carry on spontaneously.

When the energy of electrons hitting $\mathrm{SF}_{4}$ is high, the $\mathrm{SF}_{4}+\mathrm{e} \rightarrow \mathrm{SF}_{4}$ reaction will take place first, and then $\mathrm{SF}_{4}^{-}$will be decomposed due to the huge energy of the electrons, and three reactions R21-R23 may occur: $\mathrm{SF}_{4}^{-} \rightarrow \mathrm{SF}_{3}^{-}+\mathrm{F}, \mathrm{SF}_{4}^{-} \rightarrow \mathrm{SF}_{3}+\mathrm{F}^{-}, \mathrm{SF}_{4}^{-} \rightarrow \mathrm{SF}_{3}+\mathrm{F}$ + e. When the temperature of $\mathrm{R} 21$ is $298 \mathrm{~K}$, $\triangle \mathrm{G}$ is $203.3 \mathrm{~kJ} / \mathrm{mol}$, with a rise to about $2200 \mathrm{~K}$, it drops to $0 \mathrm{~kJ} / \mathrm{mol}$, when the temperature reaches $10000 \mathrm{~K}, \triangle \mathrm{G}$ is -792.3 $\mathrm{kJ} / \mathrm{mol}$. The $\triangle \mathrm{G}$ of $\mathrm{R} 22$ at $298 \mathrm{~K}$ is 242.1 $\mathrm{kJ} / \mathrm{mol}$, when the temperature rises to about $2700 \mathrm{~K}$, it drops to $0 \mathrm{~kJ} / \mathrm{mol}$, and when the temperature reaches $10000 \mathrm{~K}$, the $\triangle \mathrm{G}$ is $-687.4 \mathrm{~kJ} / \mathrm{mol}$. The $\Delta \mathrm{G}$ of $\mathrm{R} 23$ at $298 \mathrm{~K}$ is $556.3 \mathrm{~kJ} / \mathrm{mol}$, with the temperature rise to about $3700 \mathrm{~K}$, it drops to $0 \mathrm{~kJ} / \mathrm{mol}$, and when the temperature reaches $10000 \mathrm{~K}$, the $\Delta \mathrm{G}$ is $-1160.4 \mathrm{~kJ} / \mathrm{mol}$. In the temperature range of $298-5800 \mathrm{~K}$, the $\Delta \mathrm{G}$ of $\mathrm{R} 21$ is the lowest, so it 
has the highest likelihood to take place. The reaction produces SF3- and $\mathrm{F}$. The $\Delta \mathrm{G}$ of R23 is the lowest at $5800-10000 \mathrm{~K}$, and the probability of occurrence of R23 is the highest in this temperature range.

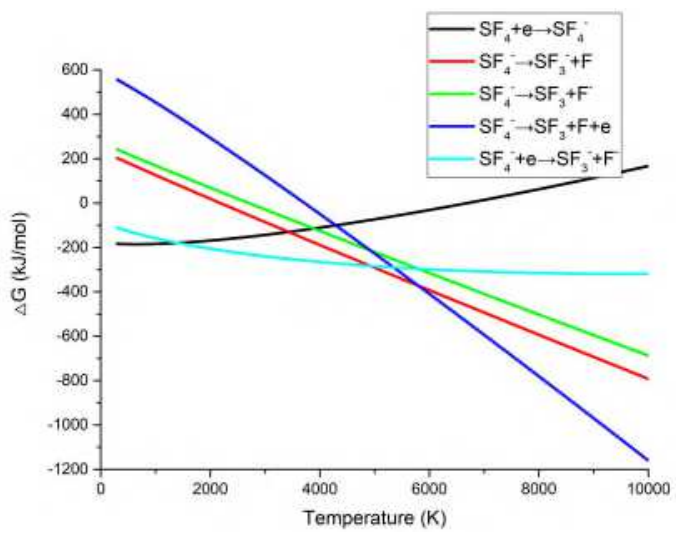

Figure 7. $\mathrm{SF}_{4}$ electron impact decomposition process $\triangle \mathrm{G}$ changes with temperature

Figure 8 shows the change of the $\Delta \mathrm{G}$ of the R28-R32 reaction at a temperature of $298-10000 \mathrm{~K}$. It can be seen from Figure 8 that the $\triangle \mathrm{G}$ of R29-R32 shows a downward trend with temperature rise, but the $\Delta G$ of $R 28$ increases with increasing temperature. When the electron energy in the space is low, the $\mathrm{R} 28$ reaction will occur: $\mathrm{SF}_{3}+\mathrm{e} \rightarrow \mathrm{SF}_{3}$. When the temperature is $298 \mathrm{~K}, \triangle \mathrm{G}$ is $-353 \mathrm{~kJ} / \mathrm{mol}$, when the temperature rises to $5000 \mathrm{~K}, \triangle \mathrm{G}$ is $-63.6 \mathrm{~kJ} / \mathrm{mol}$, when the temperature reaches $10000 \mathrm{~K}, \triangle \mathrm{G}$ is $368.1 \mathrm{~kJ} / \mathrm{mol}$, showing an upward trend as the temperature rises. When electrons continue to hit SF3-, R32 will occur: $\mathrm{SF}_{3}{ }^{-}+\mathrm{e} \rightarrow \mathrm{SF}_{2}{ }^{-}+\mathrm{F}^{-}$. When the temperature of $\mathrm{R} 32$ is $298 \mathrm{~K}, \triangle \mathrm{G}$ is $-111.9 \mathrm{~kJ} / \mathrm{mol}$, on increasing it to $5000 \mathrm{~K}, \Delta \mathrm{G}$ is $-28.8 \mathrm{~kJ} / \mathrm{mol}$, when the temperature reaches $10000 \mathrm{~K}, \triangle \mathrm{G}$ is $-4.5 \mathrm{~kJ} / \mathrm{mol}$. The $\triangle \mathrm{G}$ of this reaction is less than zero, so it can proceed spontaneously.

When the energy of electrons hitting $\mathrm{SF}_{3}$ is high, the $\mathrm{SF}_{3}+\mathrm{e} \rightarrow \mathrm{SF}_{3}$ reaction will occur first, and then $\mathrm{SF}_{3}{ }^{-}$will decompose as a result of the huge energy of the electrons, and three reactions R29-R31 may occur: $\mathrm{SF}_{3} \rightarrow \mathrm{SF}_{2}{ }^{-}+\mathrm{F}$, $\mathrm{SF}_{3}{ }^{-} \rightarrow \mathrm{SF}_{2}+\mathrm{F}^{-}, \mathrm{SF}_{3}{ }^{-} \rightarrow \mathrm{SF}_{2}+\mathrm{F}+\mathrm{e}$. The $\triangle \mathrm{G}$ of
$\mathrm{R} 29$ at $298 \mathrm{~K}$ is $426.1 \mathrm{~kJ} / \mathrm{mol}$, when the temperature rises to about $4600 \mathrm{~K}$, it drops to 0 $\mathrm{kJ} / \mathrm{mol}$, and with the temperatures at $10000 \mathrm{~K}$, the $\Delta \mathrm{G}$ is $-477.6 \mathrm{~kJ} / \mathrm{mol}$. The $\Delta \mathrm{G}$ of $\mathrm{R} 30$ at $298 \mathrm{~K}$ is $183.3 \mathrm{~kJ} / \mathrm{mol}$, when the temperature rises to about $2000 \mathrm{~K}$, it drops to $0 \mathrm{~kJ} / \mathrm{mol}$, and when the temperature reaches $10000 \mathrm{~K}$, the $\triangle \mathrm{G}$ is $-791.4 \mathrm{~kJ} / \mathrm{mol}$. The $\Delta \mathrm{G}$ of $\mathrm{R} 31$ at $298 \mathrm{~K}$ is $497.5 \mathrm{~kJ} / \mathrm{mol}$, when the temperature rises to about $3300 \mathrm{~K}$, it drops to $0 \mathrm{~kJ} / \mathrm{mol}$, and when the temperature reaches $10000 \mathrm{~K}$, the $\triangle \mathrm{G}$ is $-1264.5 \mathrm{~kJ} / \mathrm{mol}$. In the temperature range of 298-5000K, R30 has the lowest $\triangle \mathrm{G}$, so it has the highest occurrence likelihood. The reaction produces $\mathrm{SF}_{2}$ and $\mathrm{F}^{-}$. The $\mathrm{G}$ of $\mathrm{R} 31$ is the lowest at $5000-10000 \mathrm{~K}$, and the probability of occurrence of R31 is the highest in this temperature range.

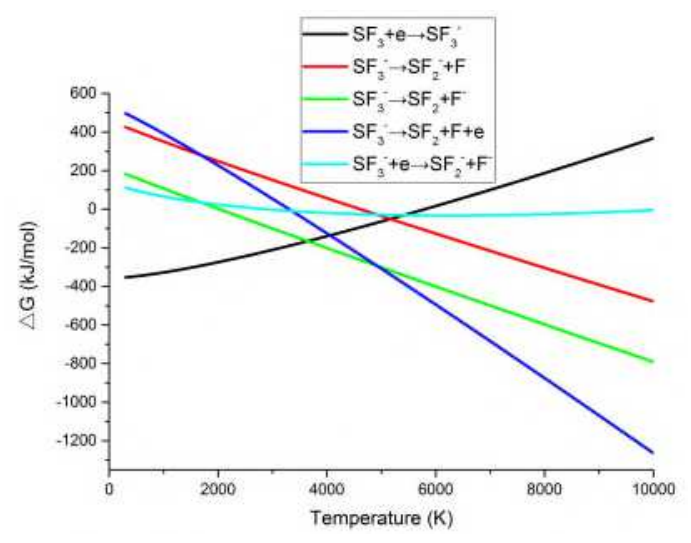

Figure $8 . \mathrm{SF}_{3}$ electron impact decomposition process $\triangle \mathrm{G}$ changes with temperature

Figure 9 shows the change of $\Delta \mathrm{G}$ of the R36-R40 reaction at a temperature of 298-10000K. It can be seen from Figure 9 that the $\triangle \mathrm{G}$ of R37-R40 shows a downward trend with increasing temperature, but the $\triangle \mathrm{G}$ of R36 increases with increasing temperature. With a low electron energy in the space, the $\mathrm{R} 36$ reaction will occur: $\mathrm{SF}_{2}+\mathrm{e} \rightarrow \mathrm{SF}_{2}^{-}$. When the temperature is $298 \mathrm{~K}$, the $\triangle \mathrm{G}$ is -71.4 $\mathrm{kJ} / \mathrm{mol}$, when the temperature is increased to $5000 \mathrm{~K}$, the $\triangle \mathrm{G}$ is $272.6 \mathrm{~kJ} / \mathrm{mol}$, when the temperature reaches $10000 \mathrm{~K}$, the $\Delta \mathrm{G}$ is $786.9 \mathrm{~kJ} / \mathrm{mol}$, showing an upward trend with 
the increase of temperature.

When electrons continue to hit $\mathrm{SF}_{2}^{-}, \mathrm{R} 40$ will occur: $\mathrm{SF}_{2}^{-}+\mathrm{e} \rightarrow \mathrm{SF}^{-}+\mathrm{F}^{-}$. When the temperature of $\mathrm{R} 40$ is $298 \mathrm{~K}, \triangle \mathrm{G}$ is $64.3 \mathrm{~kJ} / \mathrm{mol}$, when the temperature is increased to $5000 \mathrm{~K}, \triangle \mathrm{G}$ is $-191.6 \mathrm{~kJ} / \mathrm{mol}$, and when the temperature reaches $10000 \mathrm{~K}, \triangle \mathrm{G}$ is -363.6 $\mathrm{kJ} / \mathrm{mol}$. When the temperature is $298 \mathrm{~K}$, the $\Delta \mathrm{G}$ of the reaction is high, when the temperature increases, the $\Delta \mathrm{G}$ decreases, and the reaction can proceed spontaneously.

When the energy of electrons hitting $\mathrm{SF}_{2}$ is high, the $\mathrm{SF}_{2}+\mathrm{e} \rightarrow \mathrm{SF}_{2}{ }^{-}$reaction will occur first, and then $\mathrm{SF}_{2}^{-}$will be decomposed because of the huge electrons' energy, and three reactions R37-R39 may occur: $\mathrm{SF}_{2}-\mathrm{SF}^{-}$ $+\mathrm{F}, \mathrm{SF}_{2}^{-} \rightarrow \mathrm{SF}+\mathrm{F}^{-}, \mathrm{SF}_{2}^{-} \rightarrow \mathrm{SF}+\mathrm{F}+$ e. The $\triangle \mathrm{G}$ of $\mathrm{R} 37$ at $298 \mathrm{~K}$ is $170.3 \mathrm{~kJ} / \mathrm{mol}$, when the temperature rises to about $1750 \mathrm{~K}$, it drops to 0 $\mathrm{kJ} / \mathrm{mol}$, and when the temperature reaches $10000 \mathrm{~K}$, the $\triangle \mathrm{G}$ is $-1072.8 \mathrm{~kJ} / \mathrm{mol}$. The $\triangle \mathrm{G}$ of R38 at $298 \mathrm{~K}$ is $60.7 \mathrm{~kJ} / \mathrm{mol}$, when the temperature rises to about $850 \mathrm{~K}$, it is reduced to $0 \mathrm{~kJ} / \mathrm{mol}$, and when the temperature reaches $10000 \mathrm{~K}$, the $\triangle \mathrm{G}$ is $-1098.5 \mathrm{~kJ} / \mathrm{mol}$. The $\triangle \mathrm{G}$ of R39 at $298 \mathrm{~K}$ is $374.9 \mathrm{~kJ} / \mathrm{mol}$, when the temperature rises to about $2500 \mathrm{~K}$, it reduces to $0 \mathrm{~kJ} / \mathrm{mol}$, and when the temperature reaches $10000 \mathrm{~K}$, the $\triangle \mathrm{G}$ is $-1571.6 \mathrm{~kJ} / \mathrm{mol}$. The temperature is in the range of $298-4900 \mathrm{~K}$, and R38 has the lowest $\triangle \mathrm{G}$, so it has the highest occurrence likelihood. The reaction produces SF and F-. The $\triangle \mathrm{G}$ of R39 is the lowest at $4900-10000 \mathrm{~K}$, and the probability of occurrence of R39 is the highest in this temperature range.

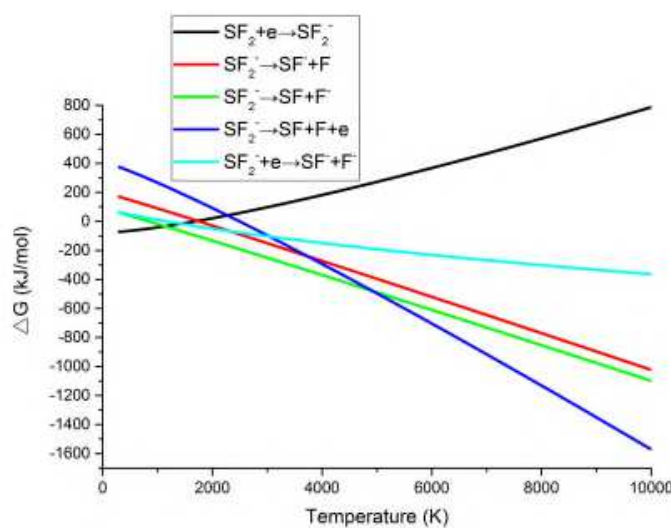

Figure 9. $\mathrm{SF}_{2}$ electron impact decomposition process $\triangle \mathrm{G}$ changes with temperature

Figure 10 shows the change of $\Delta \mathrm{G}$ in the R44-R48 reaction at a temperature of 298-10000K. It can be seen from Figure 10 that the $\triangle \mathrm{G}$ of R45-R48 shows a downward trend when the temperature is increased, but the $\triangle \mathrm{G}$ of $\mathrm{R} 44$ increases with increasing temperature. When the electron energy in the space is low, the R44 reaction will occur: SF + $\mathrm{e} \rightarrow \mathrm{SF}^{-}$. When the temperature is $298 \mathrm{~K}, \triangle \mathrm{G}$ is $-204.6 \mathrm{~kJ} / \mathrm{mol}$, when the temperature rises to $5000 \mathrm{~K}, \triangle \mathrm{G}$ is $100.2 \mathrm{~kJ} / \mathrm{mol}$, when the temperature reaches $10000 \mathrm{~K}, \triangle \mathrm{G}$ is $548.8 \mathrm{~kJ} / \mathrm{mol}$, showing an upward trend with increasing temperature.

When electrons continue to hit SF-, R48 will occur: $\mathrm{SF}^{-}+\mathrm{e} \rightarrow \mathrm{S}^{-}+\mathrm{F}^{-}$. When the temperature of $\mathrm{R} 48$ is $298 \mathrm{~K}, \Delta \mathrm{G}$ is $9.9 \mathrm{~kJ} / \mathrm{mol}$, when the temperature is increased to $5000 \mathrm{~K}$, $\triangle \mathrm{G}$ is $-140.2 \mathrm{~kJ} / \mathrm{mol}$, with the temperatures at $10000 \mathrm{~K}, \triangle \mathrm{G}$ is $-200.6 \mathrm{~kJ} / \mathrm{mol}$. At $298 \mathrm{~K}$, the $\Delta \mathrm{G}$ of the reaction is relatively low. As the temperature increases, the $\Delta \mathrm{G}$ decreases to below 0 , which was easy to occur.

When the energy of the electrons hitting the $\mathrm{SF}$ is high, the $\mathrm{SF}+\mathrm{e} \rightarrow \mathrm{SF}^{-}$reaction will occur first, and then the SF- will decompose because of the huge energy of the electrons, and three reactions R37-R39 may occur: $\mathrm{SF}^{-} \rightarrow \mathrm{S}^{-}+\mathrm{F}, \mathrm{SF}^{-} \rightarrow \mathrm{S}+\mathrm{F}^{-}, \mathrm{SF}^{-} \rightarrow \mathrm{S}+\mathrm{F}+$ e. The $\triangle \mathrm{G}$ of $\mathrm{R} 45$ at $298 \mathrm{~K}$ is $324.1 \mathrm{~kJ} / \mathrm{mol}$, when the temperature rises to about $3600 \mathrm{~K}$, it is 
minimized to $0 \mathrm{~kJ} / \mathrm{mol}$, and when the temperature reaches $10000 \mathrm{~K}$, the $\triangle \mathrm{G}$ is $-673.6 \mathrm{~kJ} / \mathrm{mol}$. The $\triangle \mathrm{G}$ of $\mathrm{R} 46$ at $298 \mathrm{~K}$ is $193.2 \mathrm{~kJ} / \mathrm{mol}$, when the temperature rises to about $2300 \mathrm{~K}$, it goes down to $0 \mathrm{~kJ} / \mathrm{mol}$, and when the temperature reaches $10000 \mathrm{~K}$, the $\triangle \mathrm{G}$ is $-781.3 \mathrm{~kJ} / \mathrm{mol}$. The $\triangle \mathrm{G}$ of $\mathrm{R} 47$ at $298 \mathrm{~K}$ is $507.4 \mathrm{~kJ} / \mathrm{mol}$, when the temperature rises to about $3500 \mathrm{~K}$, it drops to $0 \mathrm{~kJ} / \mathrm{mol}$, and when the temperature reaches $10000 \mathrm{~K}$, the $\triangle \mathrm{G}$ is $-1254.4 \mathrm{~kJ} / \mathrm{mol}$. In the temperature range of $298-4900 \mathrm{~K}, \mathrm{R} 46$ has the lowest $\Delta \mathrm{G}$, so it is most probable to take place. The reaction produces $S$ and $F$-. The $\triangle G$ of $R 47$ is the lowest at 4900-10000K, and the probability of occurrence of R47 is the highest in this temperature range.

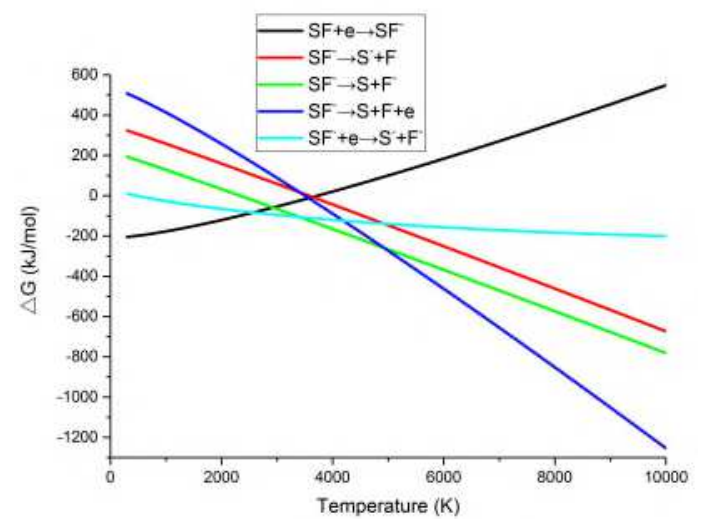

Figure 10. SF electron impact decomposition process $\triangle \mathrm{G}$ changes with temperature

We have noticed, The $\triangle \mathrm{G}$ of $\mathrm{R} 4\left(\mathrm{SF}_{6}+\right.$ $\left.\mathrm{e} \rightarrow \mathrm{SF}_{6}{ }^{-}\right)$gradually decreases with the increase of temperature, but the $\triangle \mathrm{G}$ of $\mathrm{SF}_{\mathrm{n}}+\mathrm{e} \rightarrow \mathrm{SF}_{\mathrm{n}}{ }^{-}$ $(n<6)$ increases with increasing temperature. The $\triangle \mathrm{G}$ of a chemical reaction is defined as

$$
\Delta G=\Delta H-\Delta T S
$$

Among them, $\triangle \mathrm{H}$ is the enthalpy change, $\mathrm{T}$ is the temperature, and $\triangle S$ is the entropy change. Through the previous calculations, we obtained the $\triangle H$ and $\triangle S$ of all reaction processes at the same time, and the entropy of electrons was obtained in Fifen's article. Figure 11-13 is obtained by calculating other thermodynamic data of these six reactions.
From Figure 11, it can be found that the $\Delta H$ of these six reactions decreases with the increase of temperature, and the rate of decrease is almost the same, and they are all less than zero. From Figure 12, it can be found that the entropy changes of these six reactions all decrease with the increase of temperature. The difference is that the entropy change of R4 is always greater than 0 in the temperature range of 298-10000K, while the entropy change of $\mathrm{SF}_{\mathrm{n}}+\mathrm{e} \rightarrow \mathrm{SF}_{\mathrm{n}}^{-}(\mathrm{n}<6)$ is less than 0 with increasing temperature. It can also be seen from Figure 13 that the rate of decrease of $\triangle \mathrm{T} \cdot \mathrm{S}$ product of $\mathrm{R} 4$ is much lower than that of the other five reactions, and the decrease rate of the $\Delta T \cdot S$ is lower than that of $\Delta H$. It can be seen from the definition of free energy that the $\triangle \mathrm{G}$ of $\mathrm{R} 4$ increases with increasing temperature. In the other five reactions, the $\triangle \mathrm{T} \cdot \mathrm{S}$ decrease rate is greater than the decrease rate of $\Delta H$, that is, the increase rate of $-\triangle T \cdot S$ is greater than the decrease rate of $\Delta H$. Therefore, the $\Delta G$ of $S_{n}+e \rightarrow S F_{n}{ }^{-}(n<6)$ increases with increasing temperature.

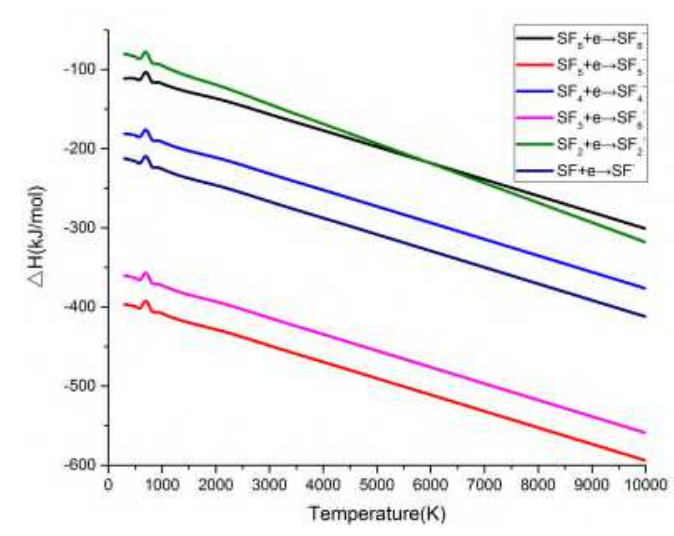

Figure 11. $\triangle \mathrm{H}$ of $\mathrm{SF}_{\mathrm{n}}+\mathrm{e} \rightarrow \mathrm{SF}_{\mathrm{n}}{ }^{-}$varies with temperature 


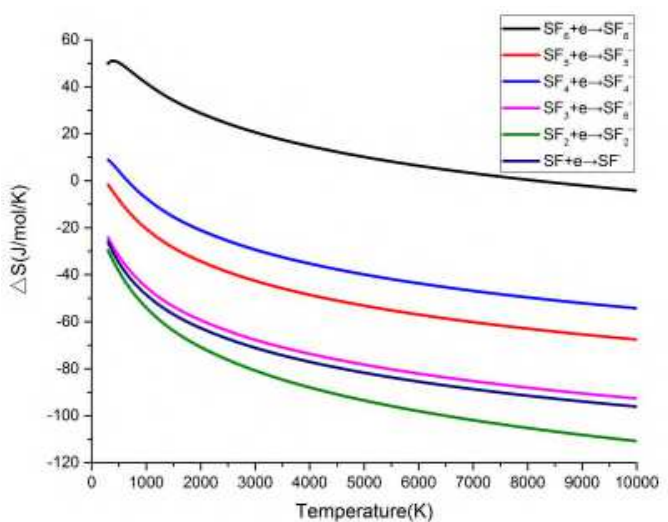

Figure 12. $\triangle \mathrm{S}$ of $\mathrm{SF}_{\mathrm{n}}+\mathrm{e} \rightarrow \mathrm{SF}_{\mathrm{n}}^{-}$varies with temperature

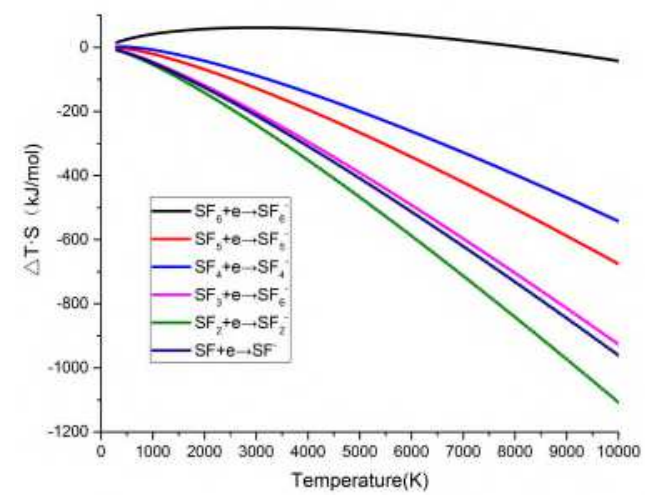

Figure 13. $\triangle \mathrm{T} \cdot \mathrm{S}$ of $\mathrm{SF}_{\mathrm{n}}+\mathrm{e} \rightarrow \mathrm{SF}_{\mathrm{n}}{ }^{-}$varies with temperature

\section{CONCLUSION}

This paper uses quantum chemistry theory to study the reaction mechanism of $\mathrm{SF}_{\mathrm{n}}$ thermal decomposition and electrical decomposition at 298-10000 K, including a total of 17 particles and 48 chemical reactions. The Gibbs free energy data of electrons are acquired by cubic spline difference fitting, and the electrons are taken into account in the reaction equation. Structural optimizations, vibrational frequency calculations, and zero-point energy calculations for the reactants and products were performed at the B3LYP/6-311++G(d,p) level of theory. The single-point energies of all species were obtained at the $\operatorname{CCSD(T)/aug-cc-PVTZ~level.~}$ The frequency vibration factor $(0.967)$ is taken into consideration. The main conclusions drawn are:

(1) In the temperature range of $298-10000 \mathrm{~K}$, the $\triangle \mathrm{G}$ of $\mathrm{SF}_{\mathrm{n}}$ thermal decomposition and homocracking reaction starts to decrease from $200 \mathrm{~kJ} / \mathrm{mol}$, while the $\Delta \mathrm{G}$ of the other two heterocracking reactions starts to decrease from $1000 \mathrm{~kJ} / \mathrm{mol}$ and $2000 \mathrm{~kJ} / \mathrm{mol}$ respectively. Both show a downward trend with an almost similar slope, and homolytic reaction is more likely to occur.

(2) In the temperature range of $298-10000 \mathrm{~K}$, the $\mathrm{SF}_{\mathrm{n}}$ electron impact decomposition process can be divided into three possibilities based on the size of the electron energy. When the electron energy is low, $\mathrm{SF}_{\mathrm{n}}+\mathrm{e} \rightarrow \mathrm{SF}_{\mathrm{n}}{ }^{-}$occurs, and the $\Delta \mathrm{G}$ of $\mathrm{SF}_{5}, \mathrm{SF}_{4}, \mathrm{SF}_{3}, \mathrm{SF}_{2}$, $\mathrm{SF}$ decomposition reaction increases with the rise in temperature, while the $\triangle \mathrm{G}$ of $\mathrm{SF}_{6}$ decomposition decreases with increasing temperature.

(3) When the electron energy is high, the electrons hitting $\mathrm{SF}_{\mathrm{n}}$ will not generate $\mathrm{SF}_{\mathrm{n}}{ }^{-}$but directly decompose $\mathrm{SF}_{n}{ }^{-}$:

In the temperature range of $298-8700 \mathrm{k}$, $\triangle \mathrm{G}$ of R5 is lowest, so it has the highest probable occurrence. $\mathrm{SF}_{6}-$ decomposition produces $\mathrm{SF}_{5}-$ and $\mathrm{F}$. In the temperature range of $8700-10000 \mathrm{~K}, \triangle \mathrm{G}$ of $\mathrm{R} 7$ is the lowest, and R7 has a greater probability of occurrence in this temperature range.

(4) In the temperature range of $298-3250 \mathrm{~K}$, the $\triangle \mathrm{G}$ of R14 is the lowest, so it will most likely occur. $\mathrm{SF}_{5}-$ decomposes to produce SF4 and $\mathrm{F}^{-}$. In the temperature range of $3250-6700 \mathrm{~K}$, the $\triangle \mathrm{G}$ of $\mathrm{R} 13$ is the lowest, and the probability of occurrence of R13 is greater in this temperature range. $\mathrm{SF}_{5}$-decomposes to produce $\mathrm{SF}_{4}{ }^{-}$and $\mathrm{F}$. When the temperature continues to rise to $6700-10000 \mathrm{~K}$, the probability of occurrence of R15 is greatest. 
(5) In the temperature range of $298-5800 \mathrm{~K}$, the $\Delta \mathrm{G}$ of $\mathrm{R} 21$ is the lowest, so it has the highest occurrence likelihood. $\mathrm{SF}_{4}^{-}$ decomposes to produce SF3- and F. In the temperature range of $5800-10000 \mathrm{~K}$, the $\triangle G$ of $R 23$ is the lowest, and the probability of occurrence of R23 is the highest in this temperature range.

(6) In the temperature range of $298-5000 \mathrm{~K}$, $\mathrm{R} 30$ has the lowest $\triangle \mathrm{G}$, so it is most probable to occur. $\mathrm{SF}_{3}^{-}$decomposition produces $\mathrm{SF}_{2}$ and $\mathrm{F}^{-}$. In the temperature range of $5000-10000 \mathrm{~K}$, the $\triangle \mathrm{G}$ of $\mathrm{R} 31$ is the lowest, and the probability of occurrence of R31 is the highest in this temperature range.

(7) In the temperature range of 298-4900K, R38 has the lowest $\triangle \mathrm{G}$, so it is most likely to occur. $\mathrm{SF}_{2}^{-}$generates $\mathrm{SF}$ and $\mathrm{F}^{-}$. In the temperature range of 4900-10000K, the $\triangle G$ of R39 is the lowest, and the probability of occurrence of R39 is the highest in this temperature range.

(8) In the temperature range of $298-4900 \mathrm{~K}$, $\mathrm{R} 46$ has the lowest $\Delta \mathrm{G}$, thus it has the highest occurrence likelihood. The decomposition of $\mathrm{SF}^{-}$produces $\mathrm{S}$ and $\mathrm{F}^{-}$. In the temperature range of 4900-10000K, the $\Delta \mathrm{G}$ of $\mathrm{R} 47$ is the lowest, and the probability of occurrence of R47 is the highest in this temperature range.

(9) When the second electron hits $\mathrm{SF}_{\mathrm{n}}{ }^{-}$, the $\mathrm{SF}_{\mathrm{n}}{ }^{-}+\mathrm{e} \rightarrow \mathrm{SF}_{\mathrm{n}-1}{ }^{-}+\mathrm{F}$. occurs. And the $\Delta \mathrm{G}$ of the reaction gradually decreases with the increase of temperature. The $\Delta \mathrm{G}$ of this series of reactions is lower and more likely to occur.

This work provides a reference for studying the by-products of the reaction of $\mathrm{SF}_{6}$ with micro water or micro oxygen.

\section{SUPPLEMENTARY MATERIAL}

See the supplementary material for the thermal decomposition reaction of $\mathrm{SF}_{4}, \mathrm{SF}_{3}$,
$\mathrm{SF}_{2}$, and $\mathrm{SF}$ in detail.

\section{Declarations}

\section{Funding}

The authors declare that this study was not funded.

\section{Conflicts of interest/Competing interests}

The authors declare that they have no known competing financial interests or personal relationships that could have appeared to influence the work reported in this paper.

\section{Availability of data and material}

The data that support the findings of this study are available within the article.

\section{Code availability}

The author's organization owns the copyright of the software program used in the article, and there is no custom code in this article.

\section{Authors' contributions}

There were equal contributions of the authors to the completion of this work.

\section{REFERENCES}

1. H. D. Lin Tao, Zhong Haifeng, Qi Yao, and Zhang Guoqiang, Transactions of China Electrotechnical Society 29 (2), 219-225 (2014).

2. T. Ziegler and G. L. Gutsev, The Journal of Chemical Physics 96 (10), 7623-7632 (1992).

3. L. N. M. Piemontesi, in 1996 IEEE International Symposium on Electrical Insulation (IEEE, MONTREAL, CANADA, 1996), pp. 828-838.

4. Y. Qiu and E. Kuffel, IEEE Transactions on Dielectrics and Electrical Insulation 6 (6), 892-895 (1999).

5. B. Belmadani, J. Casanovas and A. M. Casanovas, IEEE Transactions on Electrical Insulation 26 (6), 1177-1182 (1991).

6. R. L. Wilkins, The Journal of Chemical Physics 51 (2), 853-854 (1969). 
7. W. Frie, Zeitschrift fr Physik 201 (3), 269-294 (1967).

8. A. J. Ahearn and N. B. Hannay, The Journal of Chemical Physics 21 (1), 119-124 (1953).

9. N. Wiegart, L. Niemeyer, F. Pinnekamp, J. Kindersberger, R. Morrow, W. Zaengl, M. Zwicky, I. Gallimberti and S. A. Boggs, IEEE Transactions on Power Delivery 3 (3), 923-930 (1988).

10. Y. Wang, R. L. Champion, L. D. Doverspike, J. K. Olthoff and R. J. Van Brunt, The Journal of Chemical Physics 91 (4), 2254-2260 (1989).

11. J. J. Fifen, J Chem Theory Comput 9 (7), 3165-3169 (2013).

12. X. Wang, Q. Gao, Y. Fu, A. Yang, M. Rong, Y. Wu, C. Niu and A. B. Murphy, Journal of Physics D: Applied Physics 49 (10) (2016).

13. A. D. Becke, Phys Rev A Gen Phys 38 (6), 3098-3100 (1988).

14. F. C. Pickard, D. R. Griffith, S. J. Ferrara, M. D. Liptak, K. N. Kirschner and G. C. Shields, International Journal of Quantum Chemistry 106 (15), 3122-3128 (2006).

15. S. Canneaux, F. Bohr and E. Henon, J Comput Chem 35 (1), 82-93 (2014).

16. Y. S. Cheung, Y. J. Chen, C. Y. Ng, S.-W. Chiu and W.-K. Li, Journal of the American Chemical Society 117 (38), 9725-9733 (1995).

17. M. J. Frisch, G. W. Trucks, et al. Gaussian 09, Revision A.02, Gaussian, Inc. Wallingford CT, 2009.

18. National Insitute of Standards and Technology 2018 NIST chemistry webbook. https://webbook.nist.gov/chemistry

19. S. Y. Ye, F. Z. Deng, Journal of Huaibei Coal Teachers College (Natural Science Edition),(01):71-74, 1992. 
Figures

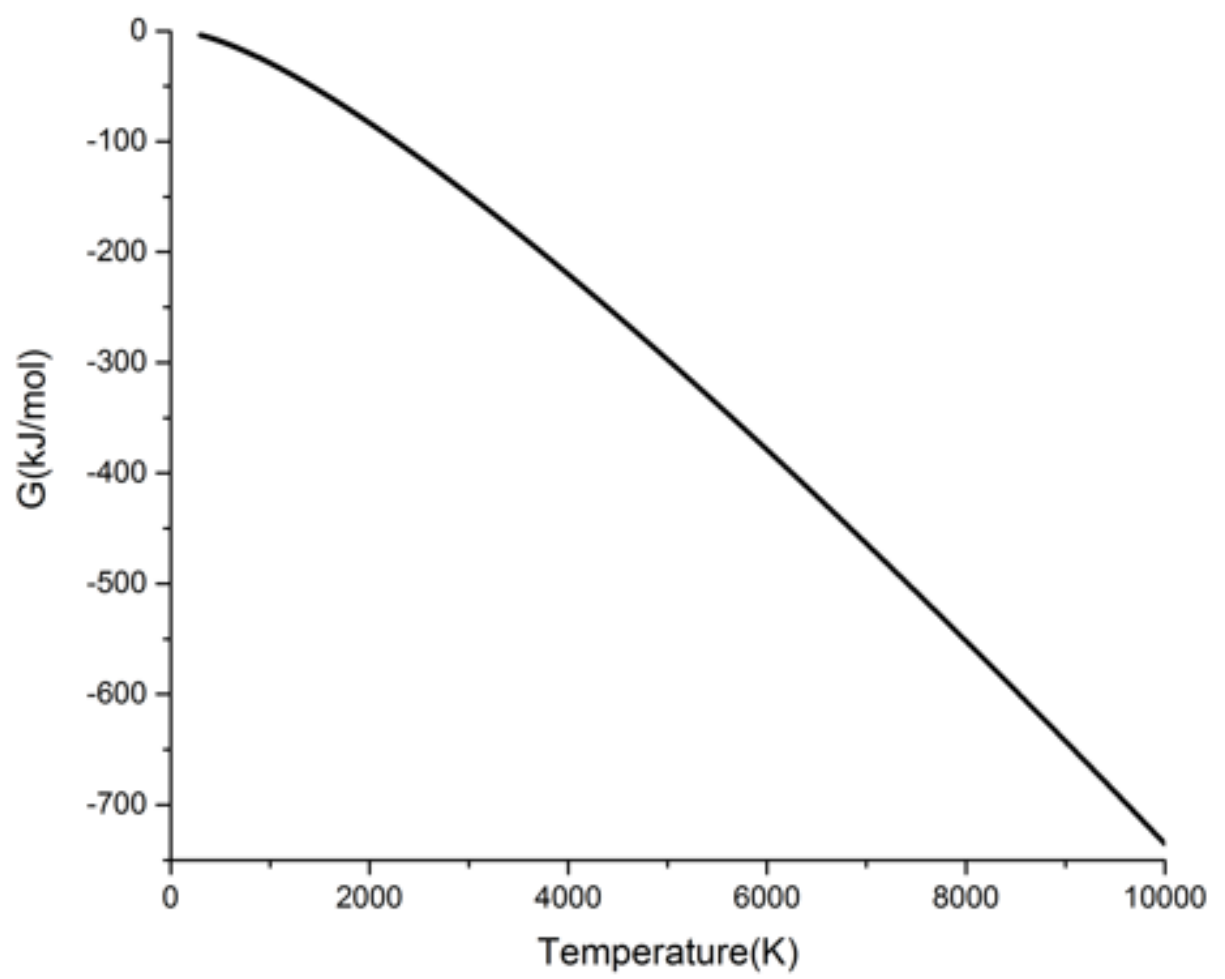

Figure 1

Gibbs free energy of gas phase electrons changes with temperature 


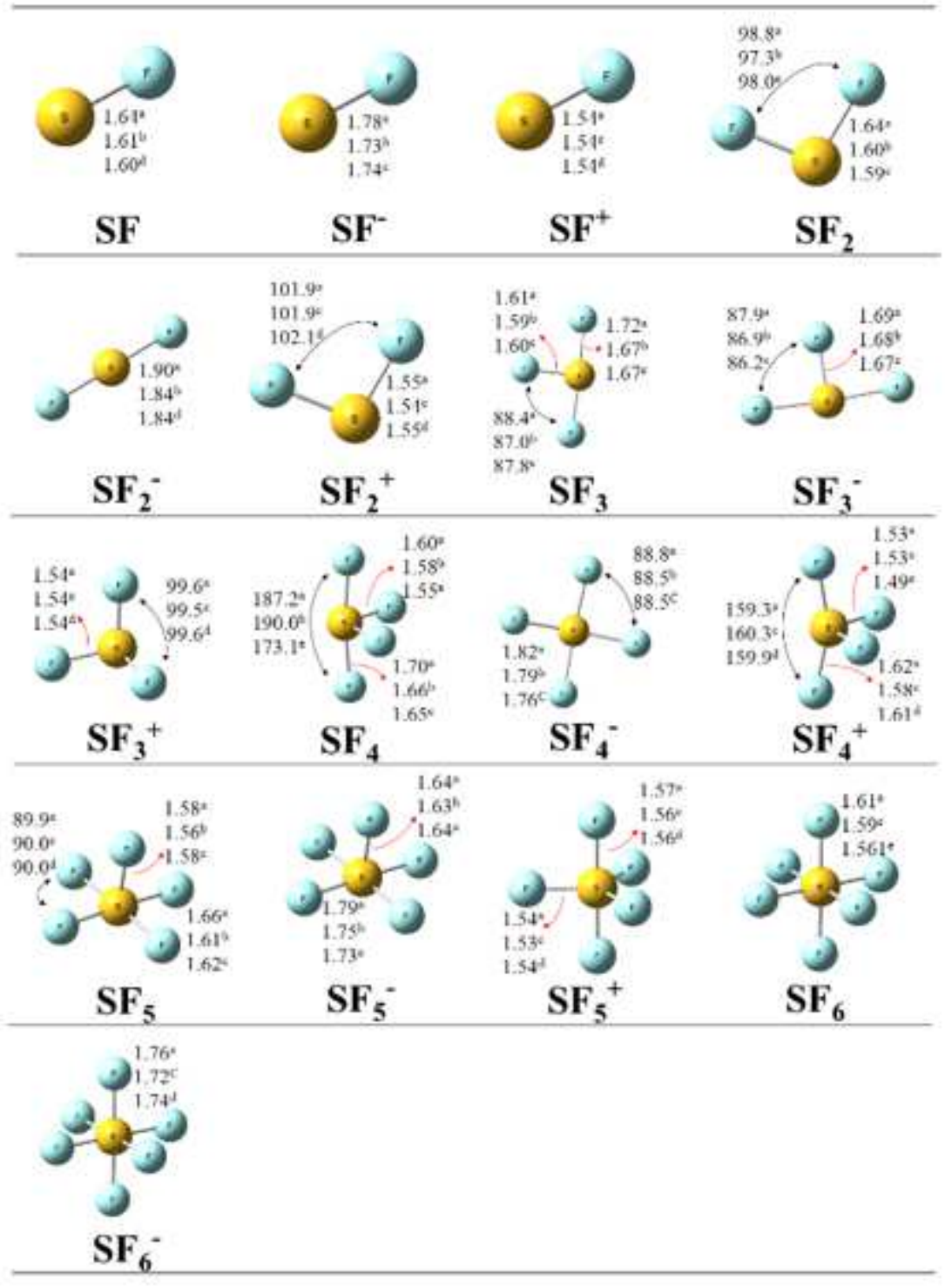

Figure 2

Optimized structures of all reactants and products. (Bond lengths are in angstroms and bond angles are in degrees.) 


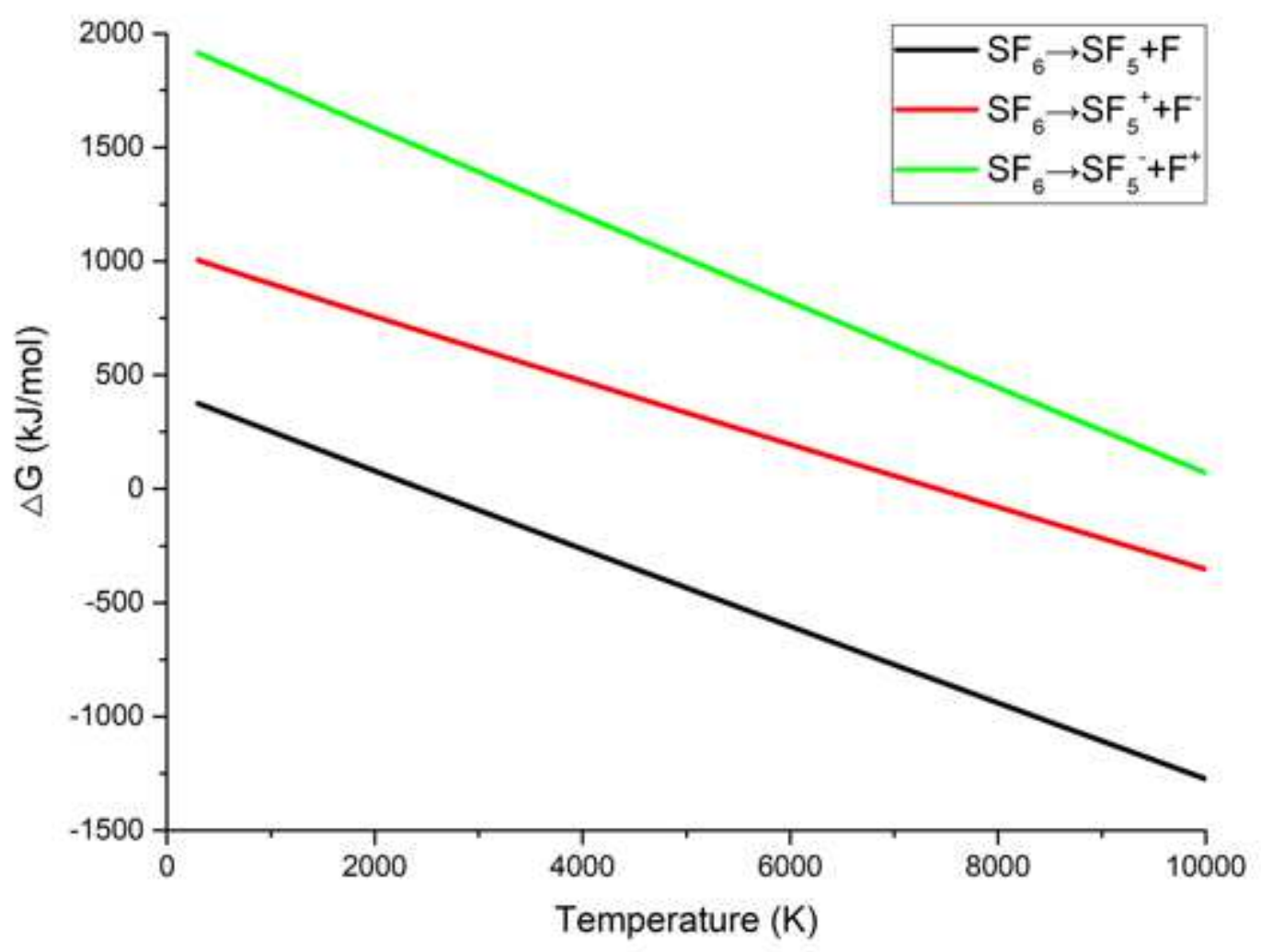

Figure 3

SF6 thermal decomposition $₫ \mathrm{G}$ changes with temperature

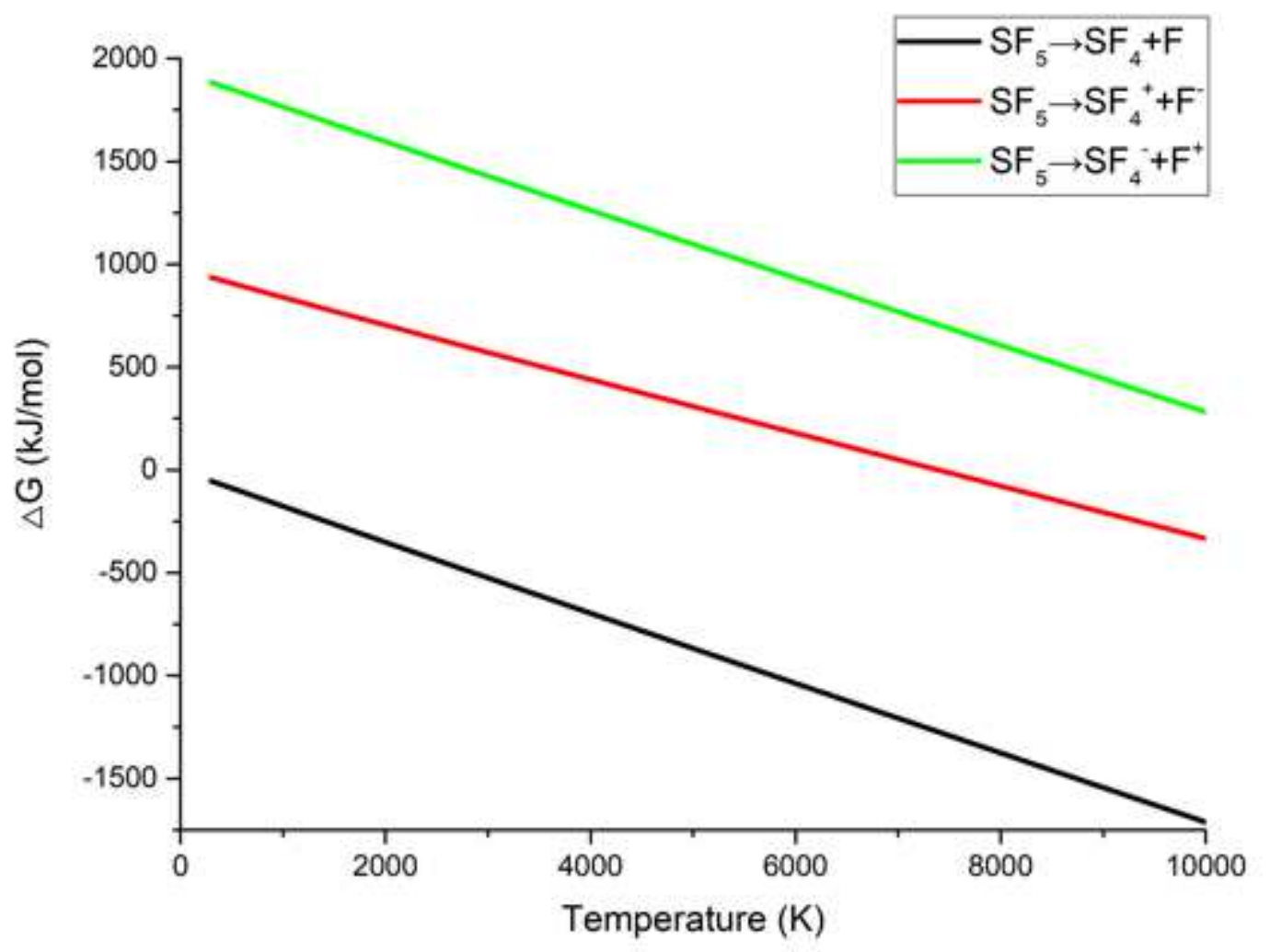

Figure 4 
SF5 thermal decomposition $\mathbb{\text { G }}$ changes with temperature

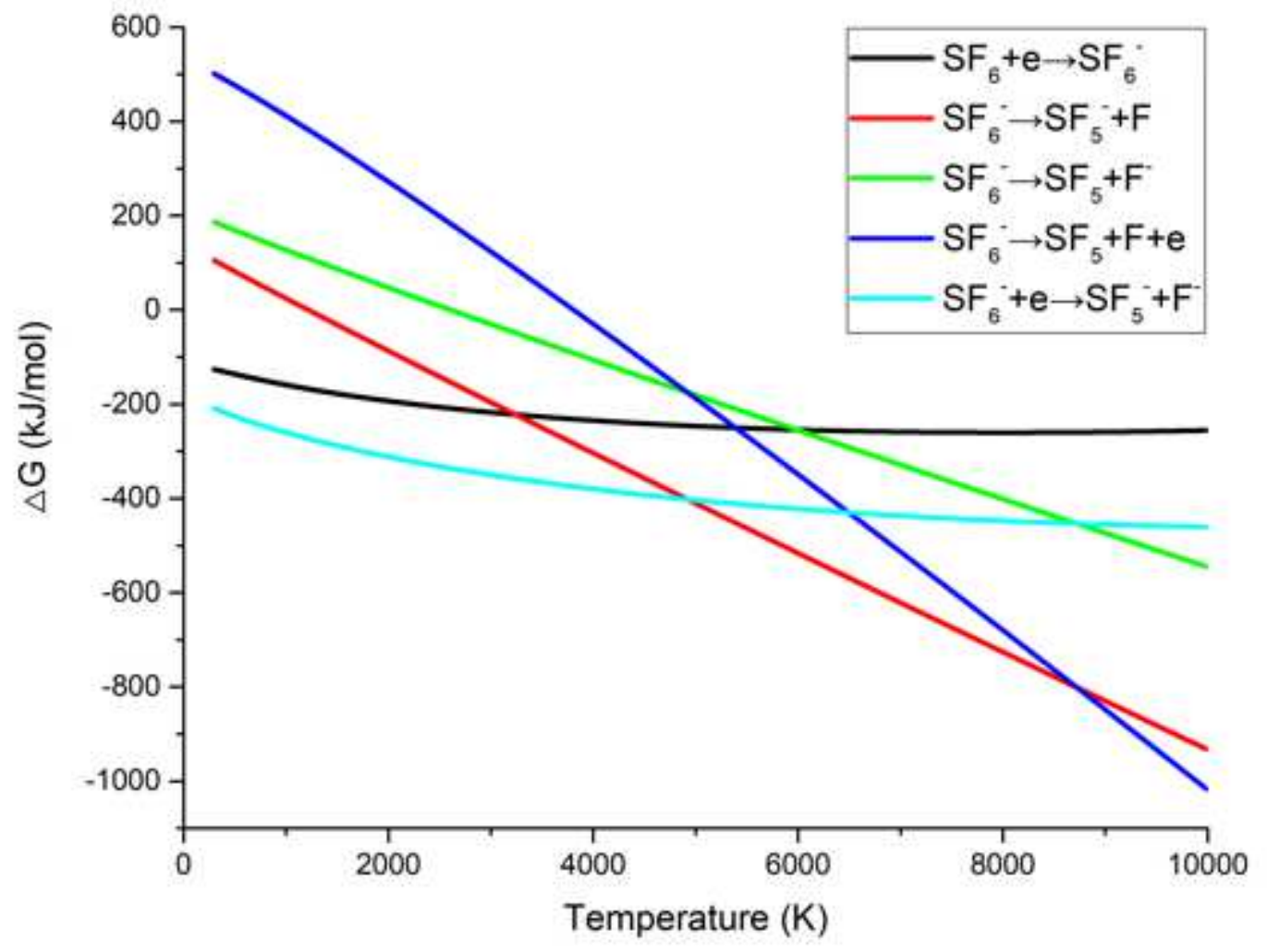

\section{Figure 5}

SF6 electron impact decomposition process $₫ G$ changes with temperature

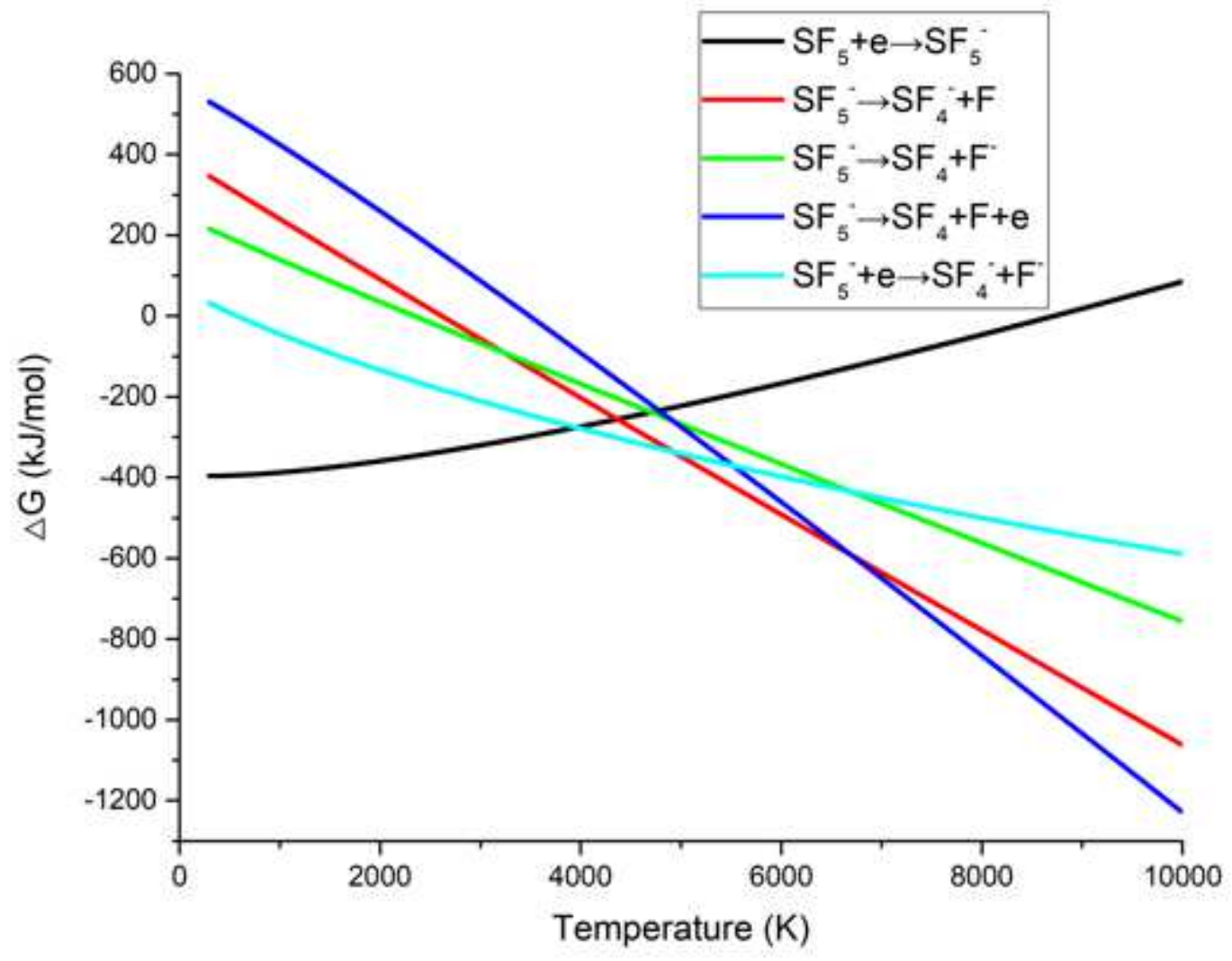


Figure 6

SF5 electron impact decomposition process

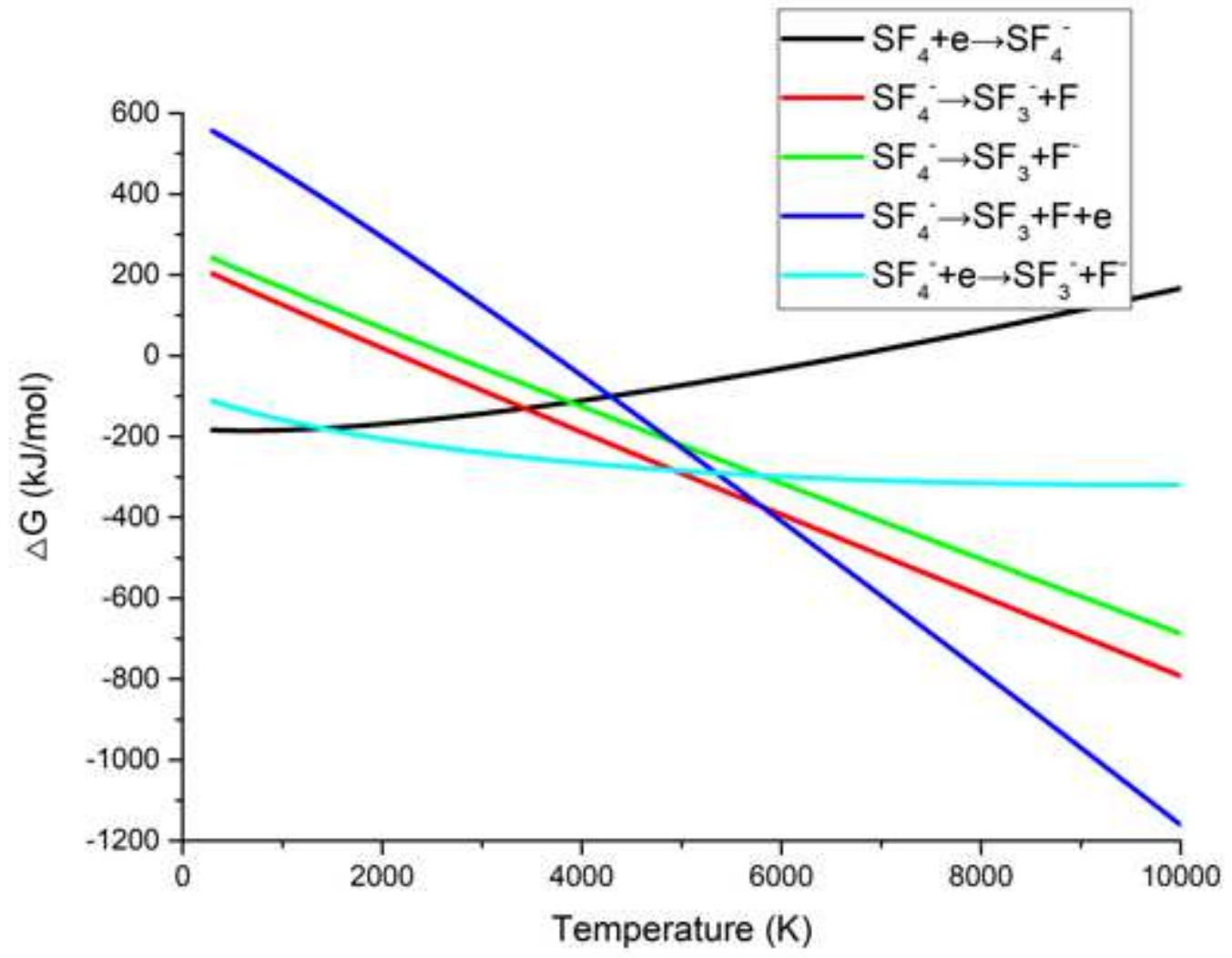

Figure 7

SF4 electron impact decomposition process $\mathbb{Q}$ changes with temperature 


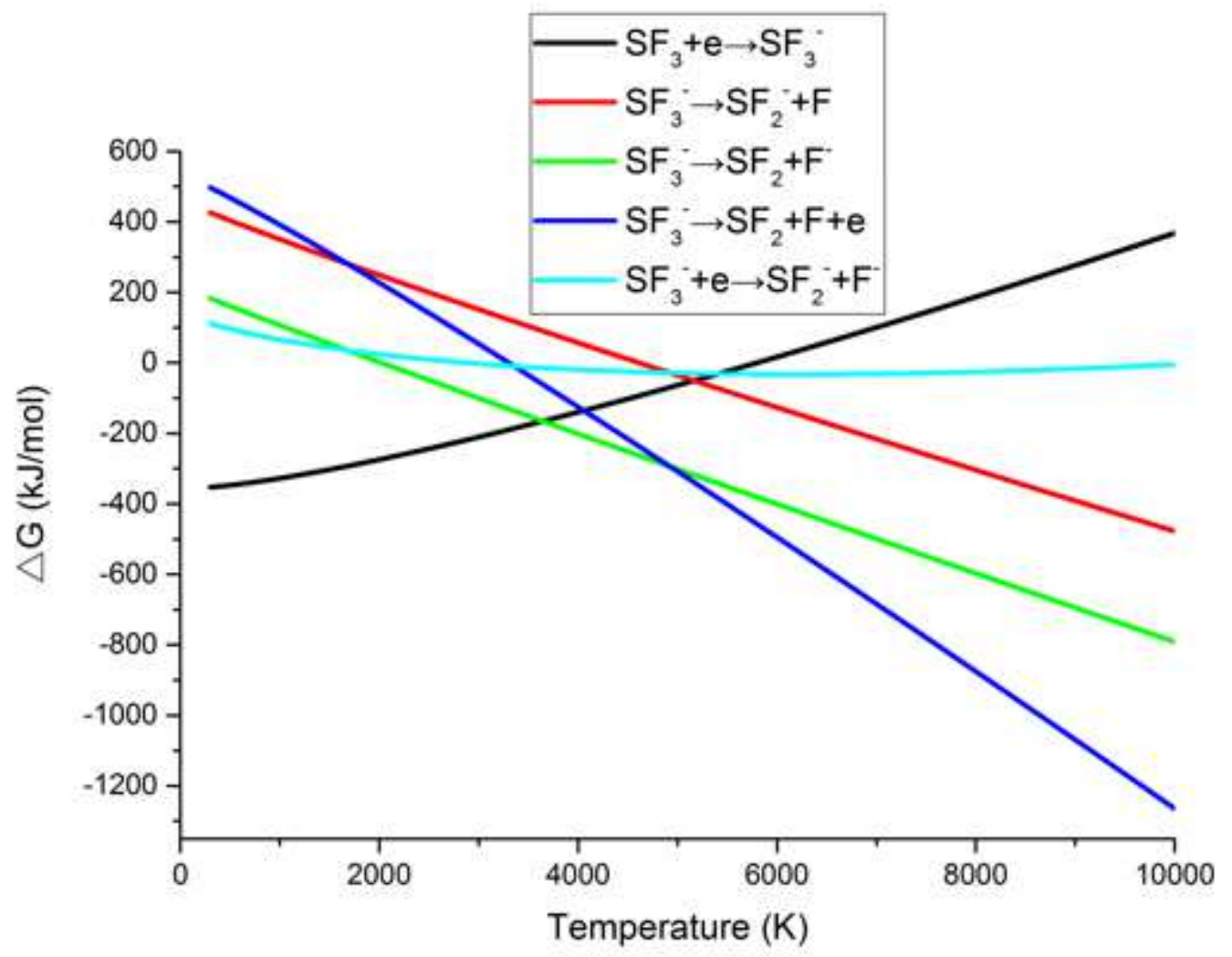

Figure 8

SF3 electron impact decomposition process $\mathbb{Q}$ G changes with temperature

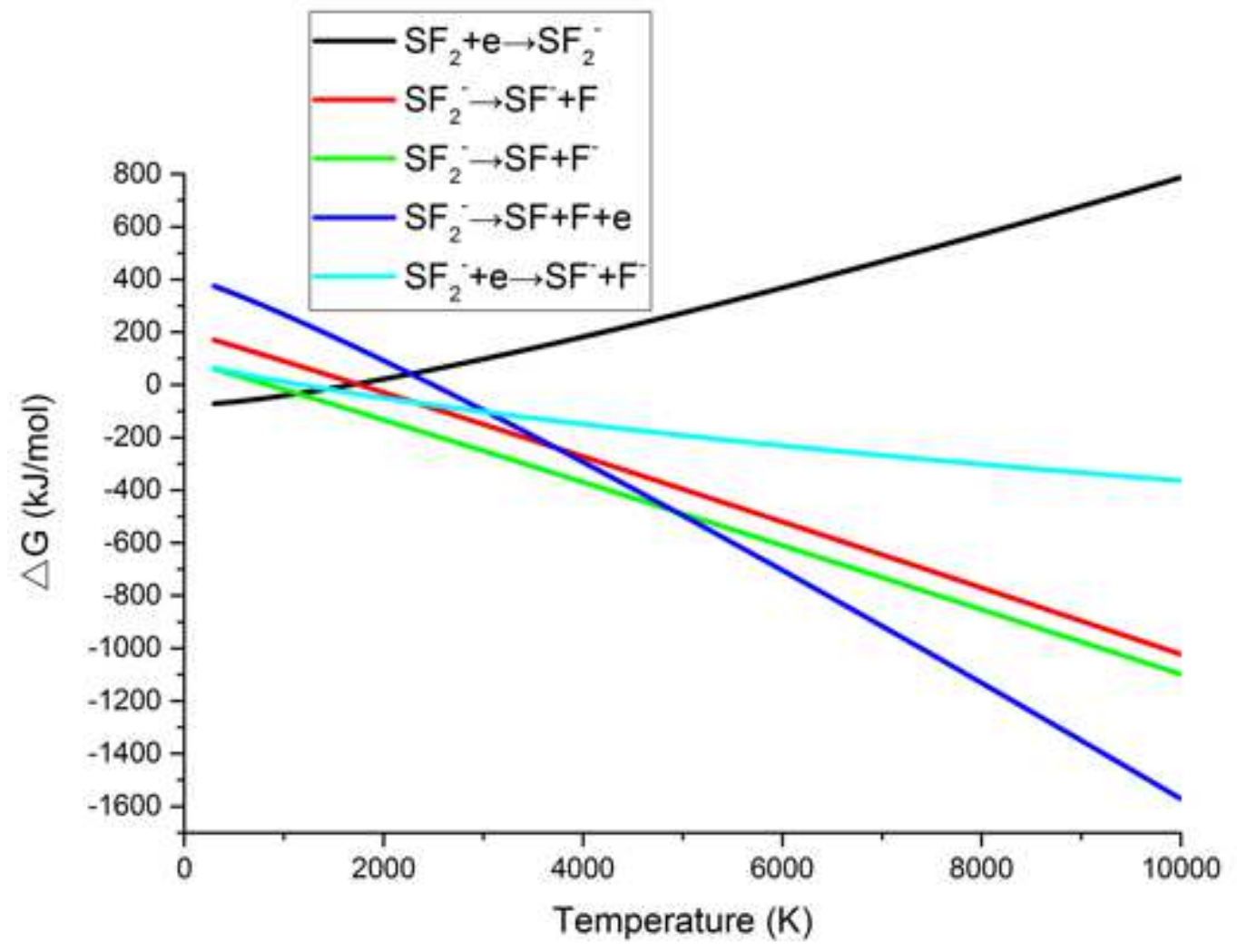


Figure 9

SF2 electron impact decomposition process $₫ \mathrm{G}$ changes with temperature

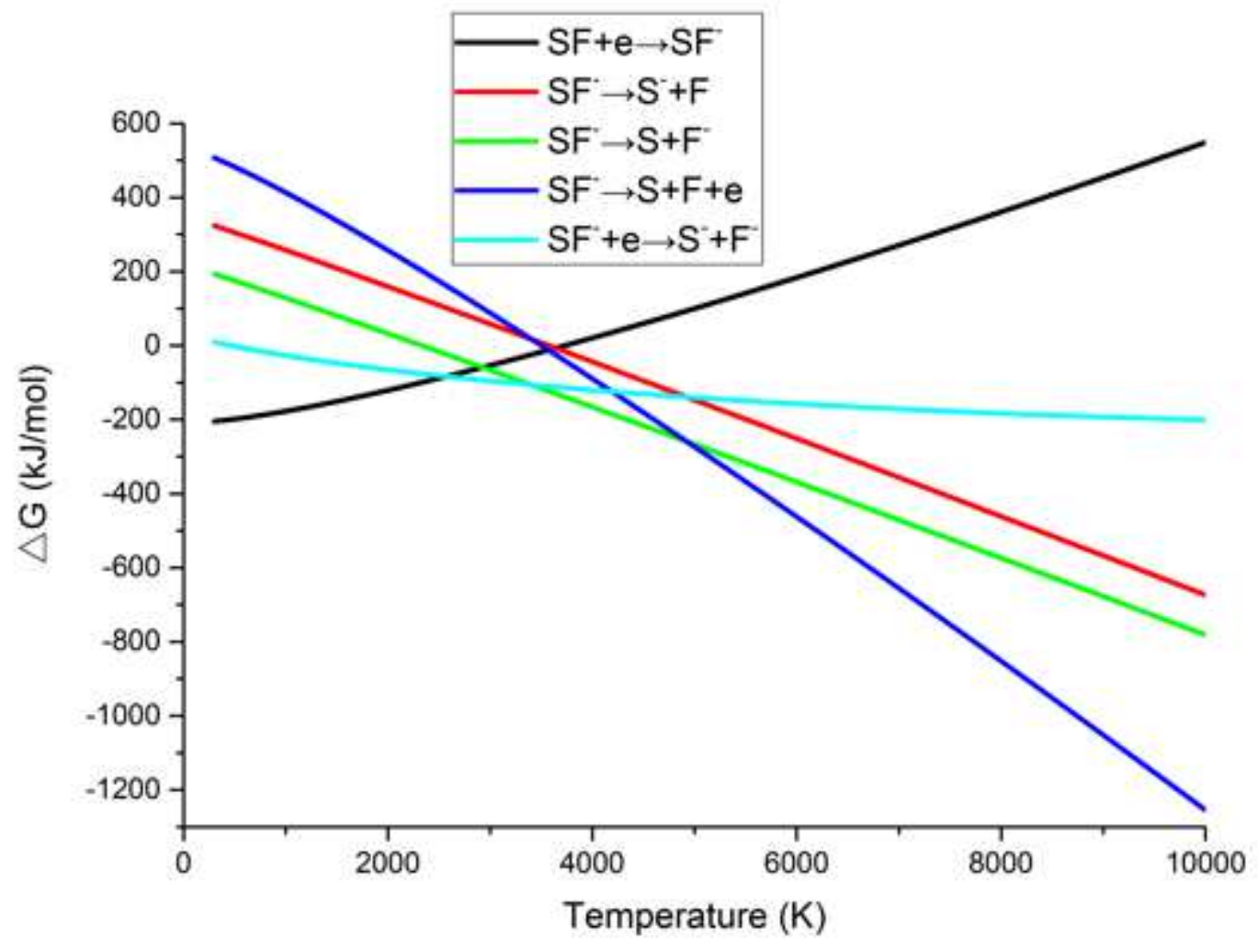

Figure 10

SF electron impact decomposition process $₫ \mathrm{G}$ changes with temperature 


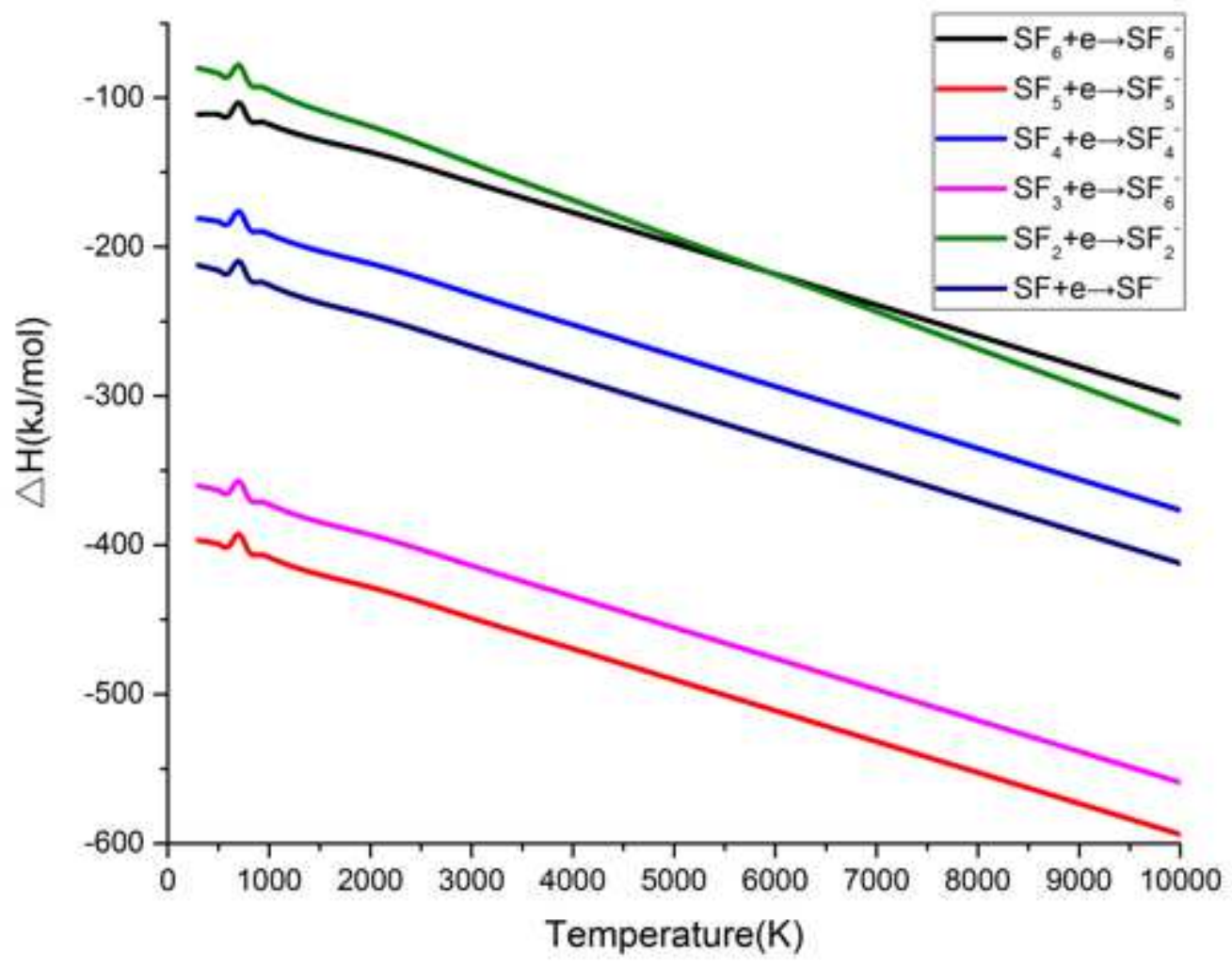

Figure 11

$\nabla H$ of $S F n+e \unrhd S F n$ - varies with temperature

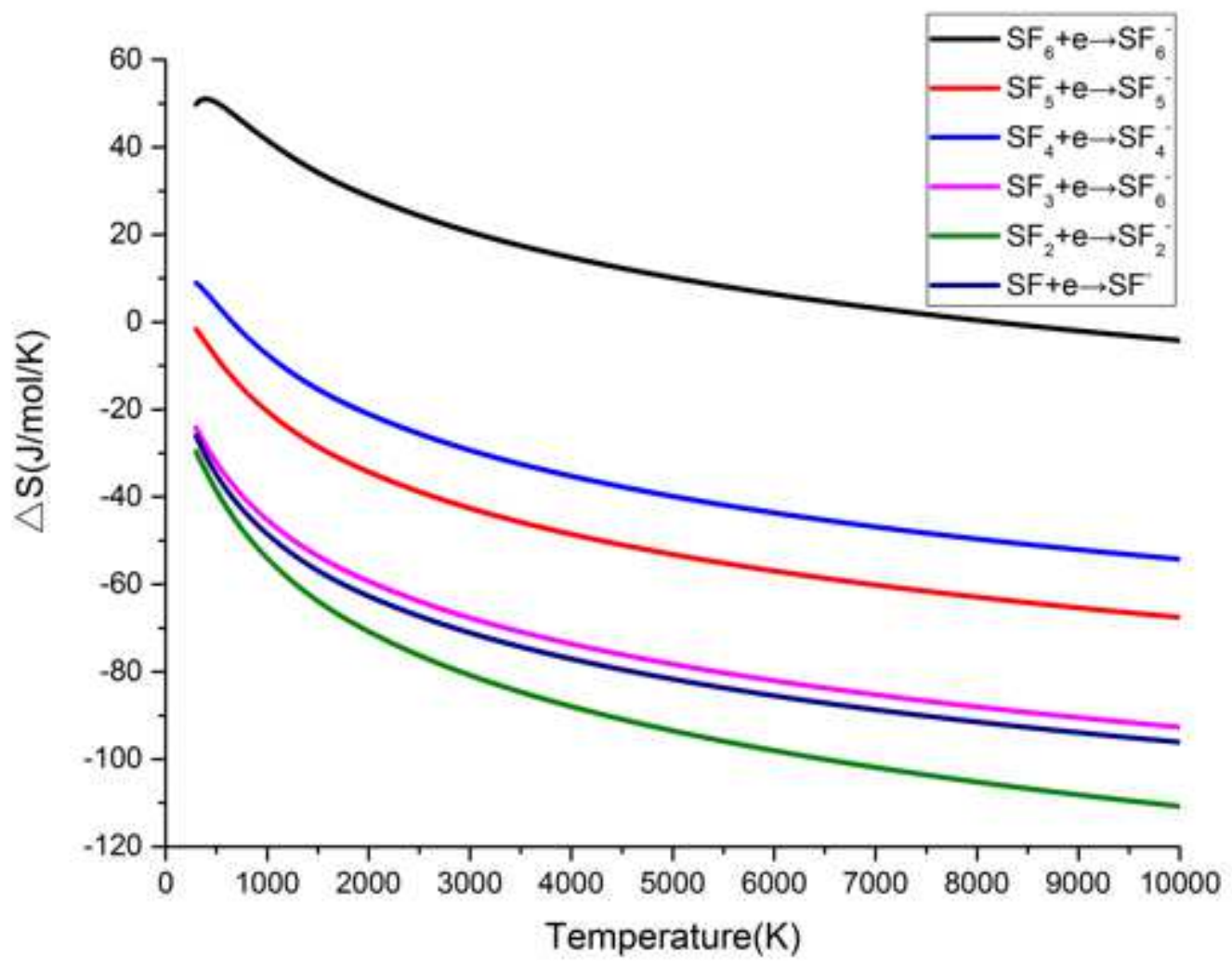

Figure 12 


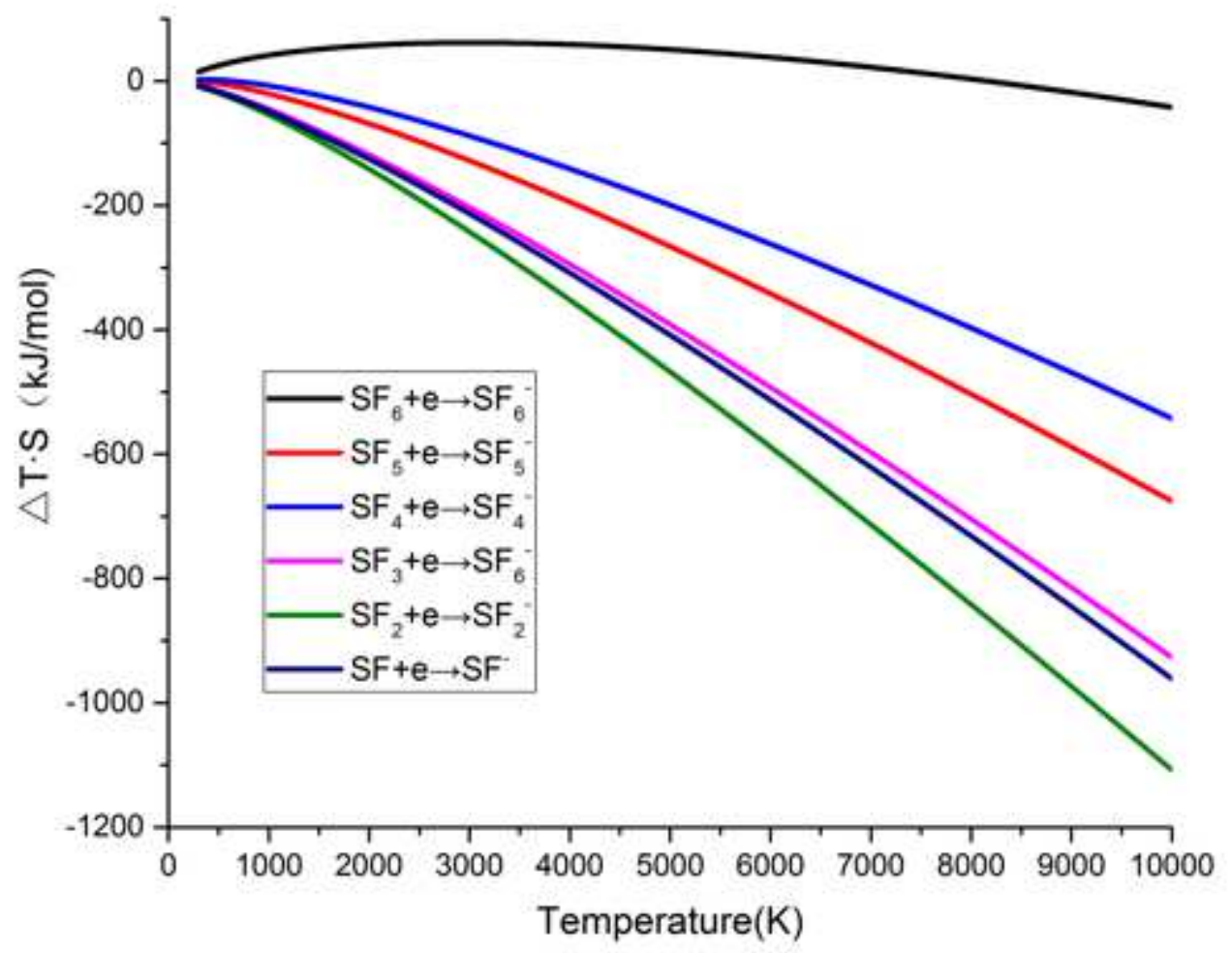

Figure 13

$\triangle T \cdot S$ of SFn + e区SFn- varies with temperature

\section{Supplementary Files}

This is a list of supplementary files associated with this preprint. Click to download.

- Supplementarymaterials.docx 